\title{
Phenolic Bioactives as Antiplatelet Aggregation Factors: The Pivotal Ingredients in Maintaining Cardiovascular Health
}

\author{
Javad Sharifi-Rad $\mathbb{D}^{1},{ }^{1}$ Cristina Quispe, ${ }^{2}$ Wissam Zam, ${ }^{3}$ Manoj Kumar ${ }^{(D},{ }^{4}$ \\ Susana M. Cardoso, ${ }^{5}$ Olivia R. Pereira, ${ }^{6}$ Adedayo O. Ademiluyi, ${ }^{7}$ Oluwakemi Adeleke, ${ }^{7,8}$ \\ Ana Catarina Moreira, ${ }^{9}$ Jelena Živković, ${ }^{10}$ Felipe Noriega, ${ }^{11}$ \\ Seyed Abdulmajid Ayatollahi, ${ }^{1,12,13}$ Farzad Kobarfard, ${ }^{1,14}$ Mehrdad Faizi, ${ }^{15}$ \\ Miquel Martorell $\mathbb{D}^{1},{ }^{16}$ Natália Cruz-Martins $(\mathbb{D}){ }^{17,18,19}$ Monica Butnariu ${ }^{(\mathbb{D},}{ }^{20}$ \\ Iulia Cristina Bagiu $\left(\mathbb{D},{ }^{21,22}\right.$ Radu Vasile Bagiu $\left(\mathbb{D},{ }^{21,23}\right.$ Mohammed M. Alshehri $\mathbb{D}^{24}$ \\ and William C. Cho ${ }^{25}$
}

\footnotetext{
${ }^{1}$ Phytochemistry Research Center, Shahid Beheshti University of Medical Sciences, Tehran, Iran

${ }^{2}$ Facultad de Ciencias de la Salud, Universidad Arturo Prat, Avda. Arturo Prat 2120, Iquique 1110939, Chile

${ }^{3}$ Department of Analytical and Food Chemistry, Faculty of Pharmacy, Al-Andalus University for Medical Sciences, Tartous, Syria

${ }^{4}$ Chemical and Biochemical Processing Division, ICAR-Central Institute for Research on Cotton Technology, Mumbai 400019, India

${ }^{5}$ LAQV-REQUIMTE, Department of Chemistry, University of Aveiro, 3810-193 Aveiro, Portugal

${ }^{6}$ Centro de Investigação de Montanha (CIMO), Instituto Politécnico de Bragança, Campus de Santa Apolónia,

5300-253 Bragança, Portugal

${ }^{7}$ Functional Foods and Nutraceuticals Unit, Department of Biochemistry, Federal University of Technology, Akure, Nigeria

${ }^{8}$ Department of Science Laboratory Technology, Ekiti State University, Ado-Ekiti, Nigeria

${ }^{9}$ Pulmonology Department, Hospital Garcia de Orta, EPE, Almada, Lisboa, Portugal

${ }^{10}$ Institute for Medicinal Plants Research “Dr. Josif Pančić”, Tadeuša Košćuška 1, 11000 Belgrade, Serbia

${ }^{11}$ Department of Plant Production, Faculty of Agronomy, Universidad de Concepción, Chillan 4070386, Chile

${ }^{12}$ H.E.J. Research Institute of Chemistry, International Center for Chemical and Biological Sciences, University of Karachi, Karachi, Pakistan

${ }^{13}$ Department of Pharmacognosy and Biotechnology, School of Pharmacy, Shahid Beheshti University of Medical Sciences, Tehran, Iran

${ }^{14}$ Department of Medicinal Chemistry, School of Pharmacy, Shahid Beheshti University of Medical Sciences, Tehran, Iran

${ }^{15}$ Department of Pharmacology and Toxicology, School of Pharmacy, Shahid Beheshti University of Medical Sciences, Tehran, Iran

${ }^{16}$ Department of Nutrition and Dietetics, Faculty of Pharmacy, and Centre for Healthy Living, University of Concepción, 4070386 Concepción, Chile

${ }^{17}$ Faculty of Medicine, University of Porto, Alameda Prof. Hernâni Monteiro, 4200-319 Porto, Portugal

${ }^{18}$ Institute for Research and Innovation in Health (i3S), University of Porto, 4200-135 Porto, Portugal

${ }^{19}$ Institute of Research and Advanced Training in Health Sciences and Technologies (CESPU), Rua Central de Gandra, 1317, 4585-116 Gandra PRD, Portugal

${ }^{20}$ Banat's University of Agricultural Sciences and Veterinary Medicine "King Michael I of Romania" from Timisoara, Timisoara, Romania

${ }^{21}$ Victor Babes University of Medicine and Pharmacy of Timisoara, Department of Microbiology, Timisoara, Romania

${ }^{22}$ Multidisciplinary Research Center on Antimicrobial Resistance, Timisoara, Romania

${ }^{23}$ Preventive Medicine Study Center, Timisoara, Romania

${ }^{24}$ Pharmaceutical Care Department, Ministry of National Guard-Health Affairs, Riyadh, Saudi Arabia

${ }^{25}$ Department of Clinical Oncology, Queen Elizabeth Hospital, Kowloon, Hong Kong
}

Correspondence should be addressed to Javad Sharifi-Rad; javad.sharifirad@gmail.com, Miquel Martorell; martorellpons@gmail.com, Natália Cruz-Martins; ncmartins@med.up.pt, Monica Butnariu; monicabutnariu@yahoo.com, and William C. Cho; chocs@ha.org.hk 
Received 19 June 2021; Accepted 28 July 2021; Published 17 August 2021

\begin{abstract}
Academic Editor: German Gil
Copyright (c) 2021 Javad Sharifi-Rad et al. This is an open access article distributed under the Creative Commons Attribution License, which permits unrestricted use, distribution, and reproduction in any medium, provided the original work is properly cited.

Cardiovascular diseases (CVD) are one of the main causes of mortality in the world. The development of these diseases has a specific factor-alteration in blood platelet activation. It has been shown that phenolic compounds have antiplatelet aggregation abilities and a positive impact in the management of CVD, exerting prominent antioxidant, anti-inflammatory, antitumor, cardioprotective, antihyperglycemic, and antimicrobial effects. Thus, this review is intended to address the antiplatelet activity of phenolic compounds with special emphasis in preventing CVD, along with the mechanisms of action through which they are able to prevent and treat CVD. In vitro and in vivo studies have shown beneficial effects of phenolic compound-rich plant extracts and isolated compounds against CVD, despite that the scientific literature available on the antiplatelet aggregation ability of phenolic compounds in vivo is scarce. Thus, despite the current advances, further studies are needed to confirm the cardioprotective potential of phenolic compounds towards their use alone or in combination with conventional drugs for effective therapeutic interventions.
\end{abstract}

\section{Introduction}

Cardiovascular diseases (CVDs) are a major cause of human mortality and morbidity in Western countries, and they are considered a huge problem for todays' health care system [1]. Parallel to the improvement of life expectancy, deaths caused by CVDs have been increasing. Currently, smoking, obesity, poor nutrition, and sedentary lifestyles comprise the main contributors [2]. Scientists estimate that by 2030, in low-income countries, the number of individuals dying from CVD will be significantly higher in comparison to other infectious diseases and nutritional disorders combined [3].

Changes in blood platelet activation are considered a specific key triggering factor for the development of CVD among others [4]. In healthy individuals, hemostatic plugs are formed as the blood clots at the bleeding site. In such situations, they are beneficial since they prevent both blood and plasma from escaping into surrounding tissue. On the other hand, thrombus expansion in the unruptured blood vessels can be harmful [5]. As a result of blood vessel injury and/or atherosclerotic plaque erosion, the endothelium liberates protein factors, enabling that way the platelets' adhesion to the subendothelium and initiating their activation. Activated platelets release biologically active ligands, including thromboxane A2 (TXA2), adenosine diphosphate, and serotonin, which further increase platelet activation, aggregation, and thrombus formation [6]. Thus, the proper control of platelet function is mandatory for the prevention of thrombotic events [7]. Indeed, platelet hyperactivity has been increasingly linked to the development and complication of certain CVDs (Figure 1), including atherosclerosis, thrombosis, peripheral artery disease, myocardial infarction, and ischemic stroke [3].

On the other side, several side effects have been reported with the currently used synthetic antiplatelet agents (aspirin, clopidogrel, and dipyridamole). For example, the chronic consumption of aspirin implies an increased risk of developing intestinal ulcers and major bleeding [6]. Moreover, these drugs are also not completely effective in suppressing platelet aggregation besides increasing the risk of drug resistance and bleeding. As a consequence, these limitations have prompted researchers to launch the quest for natural alternatives as new, effective, and safer antiplatelet drugs. In a recent review, the use of natural products as therapeutic agents has been highlighted considering the data of the last four decades (Newman and Cragg [8]). The review highlighted the use of natural products as anticancer, antidiabetic, and multiple sclerosis agents. The polyphenolic compounds present in plant-based products have been found to play the central part of many scientific studies due to their potential health benefits, with special attention being given to their positive impact on CVD [9-11]. In fact, polyphenol-rich diets have revealed a great impact on the vascular system, improving both platelet and endothelial functions [12]. Moreover, platelet activation pathways involve arachidonic acid (AA), adenosine diphosphate, serotonin, and nitric oxide (NO) pathways. Numerous medicinal plants have also demonstrated their bioactivities in reducing platelet aggregation via these mechanisms [13]. Phenolic compounds may be better for treating CVD than synthetic antiplatelet agents, addressing the problems of drug resistance and bleeding that the synthetic antiplatelet agents cannot solve. A number of reviews which focused on the role of phenolic compounds in improving the cardiovascular health have been published recently $[14,15]$. These reviews are more focused on the effect of the phenolic extracts on cardiovascular health, but limited aspects of antiplatelet aggregation activity of phenolic bioactive compounds in maintaining cardiovascular health were discussed. In this sense, considering the importance of the phenolic bioactive compounds in the management of CVDs by their antiplatelet activity, the aim of this review is to collate and summarize the finding of the researchers on polyphenolic compounds with antiplatelet activity, with emphasis on the possible molecular mechanisms responsible for their action against CVDs.

\section{Basic Structure and Physicochemical Properties of Phenolic Compounds}

Phenolic compounds account for about $40 \%$ of organic carbon circulating in the biosphere and are by definition any 

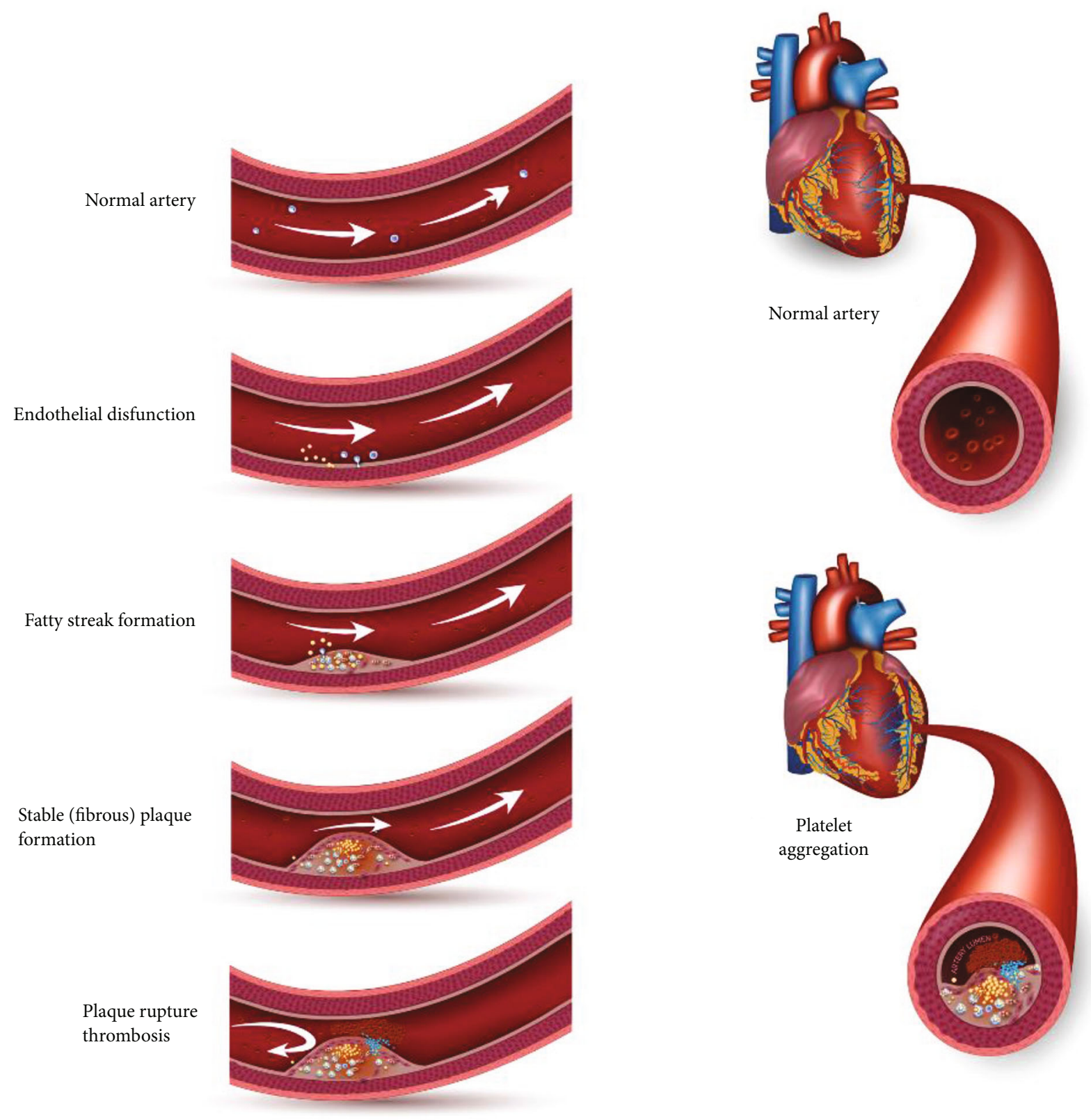

FIgURE 1: Process of platelet aggregation and formation of thrombosis during CVDs.

compound with a hydroxylated benzene ring. A polyphenolic compound has more than one phenol group, or more than one hydroxyl on a single benzene ring. Phenolic compounds come from simple, low-molecular-weight phenolic molecules to highly polymerized, high-molecular-weight, complex polyphenolic compounds [16]. They are synthesized either as soluble or cell-wall-bound compounds, generally appearing as esters and glycosides rather than free compounds. They are classified based on the number of phenolic rings that they contain and the radicals that bind the rings to one another [16]. The hydroxyl group of phenolics is influenced by the presence of the aromatic ring which makes the hydroxyl group's hydrogen labile and then makes them weak acids [16].

Water solubility increases with the number of hydroxyl groups. For analytical purposes, methanol, ethanol, water, and alcohol-water mixtures have been the most commonly used solvents to dissolve and extract phenolic compounds. The intense absorption in the spectrum of the UV region is exhibited by all phenolic compounds, and the colored ones also absorb strongly in the visible region [16].

Polyphenolic flavonoids constitute the largest group of low-molecular-weight phenolic compounds, characterized by a phenyl-benzo-pyran chemical structure consisting of two aromatic $\mathrm{C} 6$ rings ( $\mathrm{A}$ and $\mathrm{B}$ ) and a heterocyclic benzopyran ring $(\mathrm{C})$ with one oxygen atom [16]. They are crystalline compounds; some are colored, while others are colorless. They occur as aglycones, glycosides, and methylated derivatives, with differences in glycosides being attributed to the number of positions for glycosylation, types and numbers of sugars involved, and level of glycosylation. Briefly, glycosides can 
either be $\mathrm{O}$ - or C-linked in positions 3 or 7 to L-rhamnose, $\mathrm{D}$-glucose, glucorhamnose, galactose, or arabinose [16].

Phenolic acids (phenolcarboxylic acids) are members of the phenolic compounds' group containing a phenolic ring and at least one organic carboxylic acid function [16]. Tannins are water-soluble polyphenols, characterized by their relatively high molecular weight, being often found in complexes with alkaloids, polysaccharides, and proteins. Stilbenes exhibit a C6-C2-C6 structure derived from the same biosynthetic pathway as flavonoids and are featured by the presence of a 1,2-diphenylethylene nucleus with hydroxyl groups substituted on the aromatic rings [16].

2.1. Main Sources of Phenolic Compounds. According to Lattanzio [17], plant phenolic content depends on several factors, such as growing conditions, cultivation techniques, cultivar, and ripening process. In addition, while they are natural antioxidants and health promoting phytochemicals, phenolic compounds are among the health promoting phytochemicals found abundantly in plant-based foods, including fruits, vegetables, spices, and whole grains, especially cereals [17]. The subclass of flavonoids is widely addressed for their protective effects on CVDs by inhibiting platelet aggregation. Plant-based food groups are known to be richer in such compounds than others. Below, some few examples of plant-based food groups which are rich in these flavonoid compounds are presented. The concentrations of a particular flavonoid are given in $\mathrm{mg} / 100 \mathrm{~g}$ edible portion.

(i) Fruits: berries (blueberries (flavones: 7.5-19.7), raspberries (flavonols: 1.11-1.114), strawberries (flavonols: 1.3-1.65), and cranberries (flavones: 0.03)), cherry (flavonols: $2.43-28.6$ ), apple (flavones: $0.01-$ 0.12 ; flavonols: $0.42-3.87$; flavan-3-ols: $6.64-12.3$; and anthocyanidins: $0-5$ ), grape (flavonols: $1.05-$ 2.39), lemon (flavonols: 1.67; flavanones: 49.8), lime (flavonols: 0.40), banana (flavonols: 0.18), orange (flavonols: 0.22-0.73; flavanones: 29.0-42.6), pears (flavan-3-ols: 1.88-4.81; anthocyanidins: 2.06), plums (flavonols: $0.90-12.5$; anthocyanidins: $0.30-$ 558.2), peaches (flavonols: $0.45-0.88$; anthocyanidins: $0.97-1.92$; and flavan-3-ols: $1.87-16.3$ ), and apricot (flavan-3-ols: 8.41)

(ii) Cereals and legumes: soybean (flavan-3-ols: 37.4), cowpea (flavonols: 21.9), sorghum (flavones: 2.996.47; flavanones: 1.96), broad beans (flavanols: 0.9), beans (anthocyanidins: 2.74-44.5; flavan-3-ols: 0.10-324.2), purple wheat (anthocyanidins: 25.9), and peanuts (flavan-3-ols: 0.66)

(iii) Vegetables: eggplants (flavones: 0.03), onions (flavonols: 3.63-46.7; flavon-3-ols: 0-0.08; and anthocyanidins: 9.56), broccoli (flavonols: 1.05-11.2), carrots (flavonols: 0.49), cabbage (flavonols: 0.05-22.5), lettuce (flavonols: 1.63-7.63), and tomatoes (flavonols: $0.03-0.8)$

(iv) Herbs and spices: chili, coriander (flavonols: 52.9), garlic (flavonols: 3.61), ginger (flavonols: 0.19-
33.6), turmeric (flavonols: 6.96), and thyme (flavones: 47.75)

(v) Beverages: red wine (flavones: 0.04-0.17), tea (flavan-3-ols: 9.8-324.2), coffee (flavan-3-ols: 0.08; flavonols: 0.10 ), and cocoa (flavan-3-ols: 1.33-52.7)

Therefore, there is a chance of increased consumption by human on a daily basis, since they are widespread in plantbased foods and are easily absorbed due to their simplicity.

\section{Phenolic Compounds and Health Promotion}

Phenolic compounds are highly abundant secondary metabolites in the plant kingdom, possessing aromatic rings with one or more hydroxyl substituents or some functional derivatives, such as esters, methyl ethers, and glycosides [18]. Both taste and color, as well as some features of vegetables and fruits are strongly associated with the presence of such compounds, widely recognized for their wide range of activities, making them extremely beneficial to human health.

The physiological functions of phenolic compounds are vast because of their beneficial effects, not only for health promotion and maintenance but also for therapeutic purposes, given their wide range of pharmacological activities; thus, taken together, these aspects have made phenolic compounds highly important secondary metabolites and the target of an intense investigation in current times [19]. Taking a look at their versatile health benefits, they are effective antioxidant, antitumor, antimicrobial, antihyperglycemic, immunomodulatory, cardioprotective, vasodilatory, antithrombotic, antiinflammatory, and UV radiation skin protective agents, and therefore interesting candidates for pharmaceutical and medicinal applications [20-23].

Due to the medicinal plant's abundance in phenolic compounds, interesting biological activities have been reported, which are extremely useful in the prevention of the onset of age-related diseases and closely related to high oxidative stress levels. With regard to the broad-spectrum activities, there is a shift towards natural product industrialization, especially in pharmaceutical and cosmetic industries. For example, flavonoids regulate key proteins involved in inflammation and signal transduction pathways [24]. Both the absorption and metabolism of these dietary phenolic compounds determine the extent of their health benefits, which in turn are determined by their structure (conjugation with other phenolics, degree of glycosylation/acylation), solubility, and molecular size. Their effectiveness decreases with the substitution of the hydroxyl groups in their structure for sugars; thus, aglycones exhibit more potent activities than their corresponding glycosides.

\section{Phenolic Compounds That Inhibit Platelet Aggregation via Affecting Vascular Environment}

4.1. Phenolic Compounds and Cardiovascular Activity: Emphasis on Molecular Ways. The regular consumption of diets rich in fruits, vegetables, olive oil, and wine, composed 
of a wealth of phenolic compounds, exert a wide range of beneficial properties, such as antioxidant and anti-inflammatory effects as well as metabolic modulatory activities to hinder not only the disease onset but also its progression [25-28].

4.1.1. Cardioprotective Activity of Phenolics. CVD pathogenesis has been increasingly linked to oxidative stress. Typically, featured by an inflammatory condition, CVD is recognized as one of the major causes of death worldwide, with a rise in prevalence in developed countries [29]. As polyphenols are known for their antioxidant, immunomodulatory, and vasodilatory properties, an increased intake of such dietary antioxidants contributes to $\mathrm{CV}$ risk reduction [9] and inhibits oxidation of human low-density lipoproteins (LDL), ultimately preventing atherosclerotic plaque formation. The mechanisms involved in the cardioprotective effects of phenolic compounds have been studied and reported in preclinical (in vitro and in vivo) and clinical studies, acting via inhibition of ROS production, mitochondrial dysfunction, apoptosis, nuclear factor kappa B (NF- $\kappa \mathrm{B}), \mathrm{p} 53$, and DNA damage. For example, resveratrol as a case study, is a phenolic compound (stilbene) widely abundant in grapes and red wine that confers extraordinary cardioprotective effects by acutely improving endothelial function in coronary heart disease (CHD) patients [30].

Regarding CVD risk factors, hypertension is the most prominent one, contributing to one third of global mortality. Recently, naturally occurring phytochemicals have been employed not only to reduce but also to manage hypertension risk [31]. The renin-angiotensin-aldosterone (RAAS) system has been identified as an important target in the treatment/management of hypertension, myocardial infraction, stroke, and kidney diseases [32], given its role in the maintenance of vascular tone/tension. Briefly, the RAAS system mediates vascular tension via a sequential conversion of angiotensinogen to angiotensin II by a series of enzymatic cleavages. The angiotensinogen is cleaved by renin to produce angiotensin I, which is further cleaved to produce angiotensin II by the angiotensin-converting enzyme (ACE). Angiotensin II is a potent vasoconstrictor, and its presence also promotes aldosterone production, thus contributing to hypertension [32]. Hence, inhibitors of renin and ACE have shown to be beneficial in the treatment of vascular tension and as antifibrotics [33]. Recently, phenolic compounds have revealed promising effects both as ACE and renin inhibitors, with phenolic-rich foods also revealing good antihypertensive abilities in experimental models (Figure 2) [34, 35].

Experimental and clinical studies have suggested that flavonoids and flavanol-rich foods could reduce blood pressure and CVD risk in humans [36]. For instance, caffeic acid along with its 19 novel derivatives, chlorogenic acid, quercetin, and captopril showed prominent effects as inhibitors of ACE and renin, as well as modulators of aldosterone secretion [31]. Other evidences have also shown that phenolic compounds, particularly flavonoids, are able to reverse vascular endothelial dysfunction [37].

Indeed, phenolic supplementation has been shown to boost endothelial function by stimulating endotheliumderived NO bioactivity, and this may explain some of the favorable effects of high phenolic intake seen in epidemiological studies [37]. For example, a randomized controlled trial performed in pre- and hypertensive patients, revealed that olive oil enriched with its own phenolic compounds show more benefits on endothelial function than standard virgin olive oil [38].

4.2. Role of Phenolic Compounds as Antiplatelet Agent via Redox Modulation. As the largest phytochemical molecules grouped under phenolic compounds, phenolic acid and flavonoids are commonly known to have great antioxidant properties and prove to be more effective than vitamins $\mathrm{C}$ and E and carotenoids [39]. These antioxidant abilities are mediated through several mechanisms, such as scavenging free radicals, suppressing ROS formation, inhibiting some enzymes, chelating trace metals, and upregulating or protecting antioxidant defense to ensure a proper redox balance [40]. The hydrogen-donating specificity and interaction of their hydroxyl groups (acting as the antioxidant) with ROS is a termination reaction which breaks the cycle of a new radical generation. The main factor on antioxidant/reduction activity of phenolic compounds is the number and position of its hydroxyl groups which are strengthened by steric hindrance; thus, flavonoids possess more hydroxyl groups and higher antioxidant activity than the other molecules of the group $[41,42]$.

ROS are generated intracellularly and exogenously as a byproduct of normal metabolism or due to cells' exposure to some environmental triggers [43]. The imbalance between ROS generation and defense mechanism is known as oxidative stress, which is pivotal in CVD development [44, 45]. Oxidized LDL promotes vasoconstriction and progression of platelet aggregation by promoting the smooth muscle cells' proliferation and inhibiting the endothelial nitric oxide synthase (eNOS) [46].

Phenolic compounds exert an antioxidant activity via their free radical scavenging properties and inhibiting ROSgenerating enzymes (e.g., iNOS), as well as boosting antioxidant enzyme activity, like hemeoxygenase-1, glutathione peroxidase, and glutathione-S-transferase in cardiac and aortic smooth muscle cells $[44,45]$. They are also able to regulate vascular reactivity by inducing nuclear Nrf2 accumulation and targeting eNOS, thereby enhancing NO bioavailability $[47,48]$. Polyphenols also contribute to the antioxidant defense of endothelial cells by reducing NADPH oxidase expression [49]. Several in vitro studies have reported that phenolic compounds could effectively reduce oxidized LDL and increase the level of high-density lipoproteins (HDL), ultimately improving endothelial function [50, 51]. Moreover, numerous phenolic compounds exert cardioprotective effects at a localized or systemic level by inducing antiplatelet effects [46], with such effects being majorly attributed to the $O$-dihydroxyl group in the A and/or B ring (Figure 3) [52].

4.3. Role of Phenolic Compounds as Antiplatelet Agent via Inflammatory Process. Production of proinflammatory mediators during inflammation is common in some cells, mainly in macrophages, with interleukins (IL), tumor necrosis factor- (TNF-) $\alpha$, ROS, NO, and prostaglandins (PGs) being 


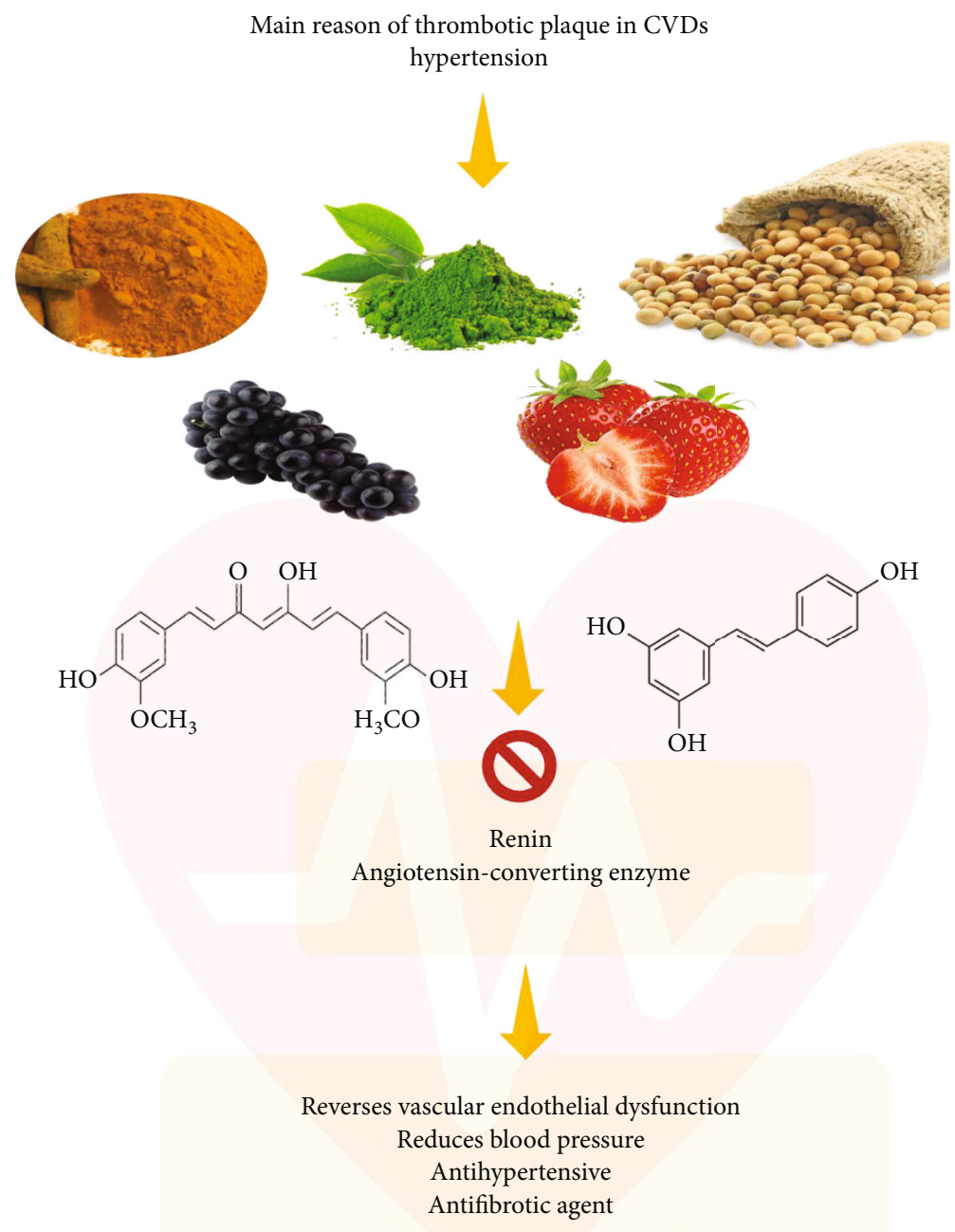

Figure 2: Antithrombotic and antihypertensive properties of the phenolic compounds.

the most commonly produced inflammation mediators [53]. Also, the association of phenolic compound structures and their anti-inflammatory activity with different targets of inflammation have been established [54]. Indeed, they are able to modulate transcriptional factors, like downregulating NF- $\kappa \mathrm{B}$ or upregulating Nrf-2 $[55,56]$. NF- $\kappa \mathrm{B}$ regulates the expression of several proinflammatory cytokines, such as IL- $1 \beta$, TNF- $\alpha$, and enzymes, like iNOS and cyclooxygenase (COX-2). Nrf-2 regulates the expression of anti-inflammatory enzymes by possessing an antioxidant responsive element (ARE) able to activate several antioxidant enzymes needed for redox balance. Thus, they inhibit the gene expression and the activity of proinflammatory mediators at the same time that they activate the expression and activity of anti-inflammatory mediators that are targets of transcription factors.

The inhibition of inflammatory mediators, such as ROS, NO, and PGE2, and proinflammatory mediators, like cytokines, TNF- $\alpha$, and COX-2, is one of the major targets for CVD treatment (Figure 3). The overexpression of TNF- $\alpha$ and IL is linked to NF- $\kappa \mathrm{B}$ activation, which regulates the release of inflammatory mediators [57]. Additionally, phos- phorylation of p38 mitogen-activated protein kinases (MAPK) plays an important role in chronic inflammation by activating NF- $\kappa \mathrm{B}$ as well as regulating the NO and proinflammatory gene production from macrophages $[58,59]$.

Procyanidins were found to reduce the protein expression of iNOS, COX-2, lipoxygenase- (LOX-) 15 and some proinflammatory cytokines, such as IL- $1 \beta$, TNF- $\alpha$, and monocyte chemoattractant protein- (MCP-) $1[58,60,61]$. These effects might be due to suppression of NF- $\kappa \mathrm{B}$ activity via downregulation of p38 and MAPK pathways [44, 58]. Rius et al. [62] proved that resveratrol supplementation may partially protect against CVD especially during the early atherosclerotic phase. This effect could be due to a decrease in the overexpression of intercellular and vascular cell adhesion molecules by inhibiting the NF- $\kappa \mathrm{B}$ pathway in TNF- $\alpha$-activated endothelial cells [63], and other reports have shown that it is related to a reduction of circulating levels of MCP-1 and MIP- $1 \alpha$ [62]. Polyphenols extracted from roasted cocoa beans suppressed inflammation via oxidative pathways, which lead to an increase in oxygen consumption by mitochondria and ATP production via oxidative phosphorylation [64]. 


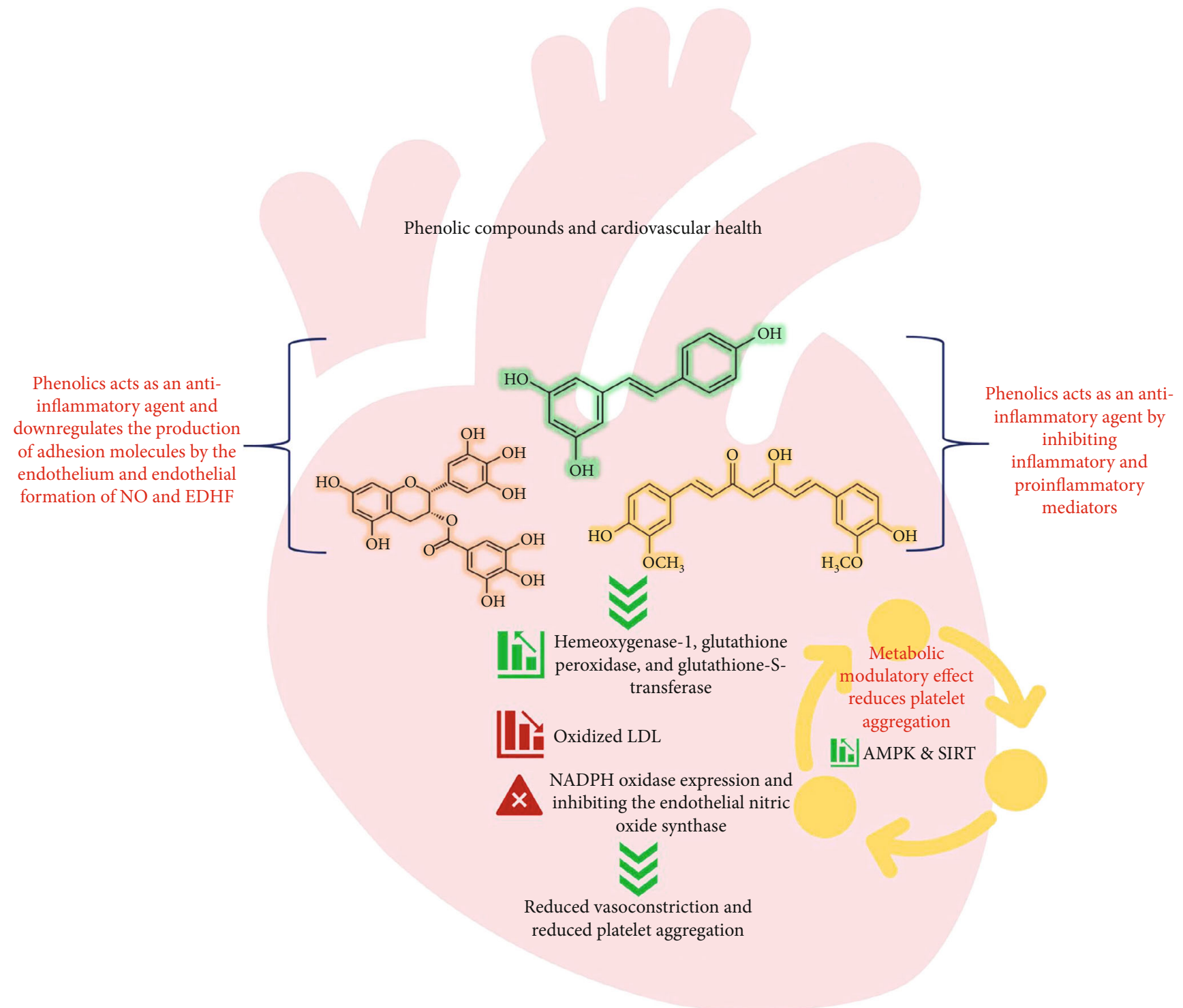

Figure 3: Role of phenolics as antiplatelet factors via redox modulation, anti-inflammatory responses, and metabolic modulatory effect.

As stated above, phenolic compounds present in extravirgin olive oil have also been stated to be potent anti-inflammatory agents by preventing the expression of iNOS, COX-2, LOX, and phospholipase A2 and thus blocking the production of eicosanoids (PGI2, leukotriene B4) [65]. They can also reduce platelet aggregation by decreasing the production of thromboxane B2 (TXB2) and 27-hydroxyleicosatetraenoate [66]. The same findings have also been said about resveratrol, which forms stable complexes in platelet COX-1 channels [67]. Moreover, the supplementation with curcumin or cinnamon bark extract was able to reduce the levels of C-reactive protein (CRP), an acute phase protein that plays a key role in CVD progression $[68,69]$. The potential therapeutic and healthpromoting roles of curcumin are also highlighted in the recent review by Moballegh Nasery et al. [70].

On the other hand, endothelial dysfunction results in the formation of vasoconstrictive factors, such as endothelin-1 in the arterial wall, implicated in CVD development [71].
Dietary polyphenols have also been shown to downregulate the production of adhesion molecules by the endothelium and to modify the endothelial formation of $\mathrm{NO}$ and endothelium-derived hyperpolarizing factor (EDHF), which improve endothelial function [9].

4.4. Role of Phenolic Compounds as Antiplatelet Agents via Metabolism Modulation. CVDs are related to alterations in metabolism. Dasgupta and Milbrandt in 2007 found that resveratrol can target and activate AMP-activated protein kinase (AMPK), having an important role in reducing fat accumulation, cholesterol synthesis, and inflammatory cytokines [72]. Resveratrol could also stimulate sirtuin 1 (SIRT1) at an amplitude of $\sim 10$-fold, which is a NAD-dependent lysine deacetylase that plays a vital role in energy metabolism (Figure 3) [73]. SIRT1 is known to regulate a variety of cell functions, mainly mitochondrial function, by activating the transcriptional activity of peroxisome proliferator-activated 
receptor-gamma coactivator- (PGC-) $1 \alpha$ and triggering the activation of AMPK [74, 75]. Stimulation of SIRT1 and AMPK boosts the eNOS activity in human coronary arterial endothelial cells and increases NO production and mitochondrial biogenesis, which triggers vasodilation and decreases atherosclerosis [76]. Recent data have shown that polyphenols interact directly with the activator site of both estrogen receptor- (ER-) $\alpha$ and ER- $\beta$, leading to eNOS activation and stimulation of NO production and endotheliumdependent vasorelaxation $[77,78]$.

\section{Phenolic Compounds with In Vitro Antiplatelet Aggregation Activity}

The inhibition of platelet aggregation and thrombus formation comprises a vital target in preventing atherosclerotic events [79]. This concept has motivated researches to find therapeutic strategies targeting to reduce platelet aggregation. In fact, diets rich in phenolic compounds could represent a natural alternative for inhibiting platelet aggregation in a dose-dependent manner and helping reduce the individual risk of developing CVD [80]. From a mechanistic point of view, the inhibitory activity of phenolic compounds greatly depends on the phenolic class and is mainly due to their anti-inflammatory and antioxidant capacities, with an $\mathrm{IC}_{50}$ in the range of $\mu \mathrm{M}$ [81]. Pignatelli et al. [82] have reported that a combination of $25 \mu \mathrm{M}$ catechin/L and $5 \mu \mathrm{M}$ quercetin/L can synergistically inhibit platelet aggregation by blunting hydrogen peroxide production. Wang et al. [83] reported that kaempferol inhibits NADPH oxidase, thus reducing the ROS production. Similarly, Meshkini and Tahmasbi reported in 2017 that the antiplatelet activity of walnut hull extract is linked to its capacity to inhibit the rise in ROS levels induced by thrombin in platelets [7]. Cocoa polyphenols reduced platelet NADPH oxidase activation and the platelet formation of ROS and eicosanoids [84].

The main reported mechanisms of action for phenolic compounds, other than the antioxidant effects, include the suppression of cytoplasmic $\mathrm{Ca}^{2+}$ increase and inhibition of thromboxane formation and AA pathway [81, 85]. Quercetin was found to completely inhibit AA-induced platelet aggregation at $200 \mu \mathrm{M}$ [86] and to inhibit platelet aggregation induced by thrombin by impairing $\mathrm{Ca}^{2+}$ mobilization and serotonin secretion [87]. Resveratrol could also inhibit the arachidonate-dependent synthesis of inflammatory agents, such as TXB2, hydroxyheptadecatrienoate, and 12hydroxyeicosatetraenoate [67]. Apart from the antiplatelet activity of resveratrol, it also modulates the expression of noncoding RNAs in ovarian cancer cells (Vallino et al., 2020). Another study also showed the anticancer activity of resveratrol by inhibiting the STAT3 signaling pathway (Baek et al., 2016). Similarly, resveratrol might improve cardiovascular health by affecting the gene expression of platelet aggregating factors. Son et al. [88] reported that green tea catechins exert antithrombotic effects through the inhibition of TXA2 formation by modulating AA liberation and TXA2 synthase. Rutin and $\alpha$-naphthoflavone have also been shown to inhibit phosphoinositide breakdown and several other steps, such as
$\mathrm{Ca}^{2+}$ mobilization, protein kinase $\mathrm{C}(\mathrm{PKC})$ activation, and TXA2 formation in collagen-activated platelets $[89,90]$.

Flavonoids also inhibit the platelets' stimulation through phosphoinositide 3-kinase (PI3K)/PKB (AKT) and by extracellular signal-regulated kinase (ERK) 1/2, p38, and cJun Nterminal kinase (JNK) 1/2 pathways [91]. Several researches proved that quercetin at $50-60 \mu \mathrm{M}$ completely inhibits all PI3k isoforms [92]. Moreover, some flavonoids have been shown to inhibit phospholipase C, platelet-activating factor, or collagen-receptor antagonism and glycoprotein IIb-IIIa activation [93]. It has also been revealed that quercetin and catechin are able to downregulate the expression of GPII$\mathrm{b} / \mathrm{III}$ in platelets by increasing the NO production [94]. Hydroxytyrosol acetate and hydroxytyrosol were also found to synergistically inhibit collagen-induced platelet aggregation [95]. The inhibition of phospholipases, tyrosine kinases, phosphodiesterases, LOX, and COX are other mechanisms involved [96]. In silico docking studies showed that resveratrol could form stable complexes in platelet COX-1 channels [67], while Hubbard et al. [97] concluded that quercetin inhibits collagen-induced phosphorylation mainly due to its tyrosine-kinase inhibitory activity.

From the point of view of a structure-activity relationship (Figure 4), the hydroxyflavones were more effective than their corresponding methoxyflavones, considering that the hydroxyl group position also influences platelet function [98]. This is explained by the fact that methylation changes the electrical charge of the flavonoid and so decreases its affinity for TXA2 receptors. Glycosylation also decreases the antiplatelet activity of flavonoids by enlarging their size, thus complicating binding to the receptor [85]. The double bond in $\mathrm{C} 2-\mathrm{C} 3$ and/or $4-\mathrm{C}=\mathrm{O}$ in the C-ring of flavonoids has also a key importance for the antiplatelet activities [99]. It was also observed that not only does the phenyl group of a $\mathrm{B}$ ring play a critical role in antiplatelet activity, but the heteroatoms of the B ring also largely influence this activity [98].

Data have also shown that apigenin, genistein, and luteolin have high affinity to the TXA2 receptor due to their structural characteristic conjugation, with the presence of a lactone structure [85]. Indeed, epigallocatechin gallate, catechin gallate, and epicatechin gallate are catechins containing a galloyl group in the $3^{\prime}$ position, all inhibiting thrombininduced aggregation and phosphorylation of p38 MAPK and ERK1/2. Catechins without a galloyl group (catechin, epicatechin) or with a galloyl group in the $2^{\prime}$ position (epigallocatechin) did not inhibit platelet aggregation [100].

\section{Phenolic Compounds with In Vivo Antiplatelet Aggregation Activity}

In vitro evidence cannot be fully translated to the in vivo condition in animals because parent molecule administration is followed by the presence of conjugated metabolites in the plasma with lower biological effects [101]. Additionally, experimental data related to the antiplatelet aggregation activity of dietary polyphenols in vivo are scarce, and results are often conflicting. For example, Ostertag et al. [102] demonstrated in an ex vivo study that phenolic compounds affect 


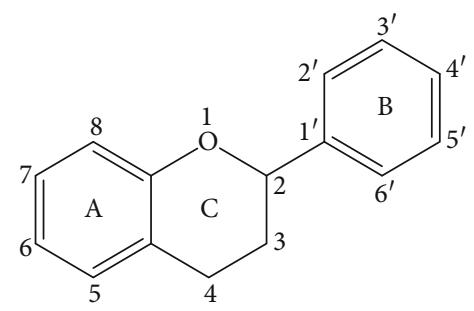

FIgURE 4: Basic structure of flavonoids.

the collagen-induced platelet aggregation and thrombin receptor-activating peptide-induced $\mathrm{P}$-selectin expression but only at very high nonphysiologically attainable concentrations. In streptozotocin-induced diabetic rats, Schmatz et al. [103] also proved in an ex vivo study that moderate consumption of grape juice and red wine modulates the hydrolysis of the adenine nucleotides and decreases platelet aggregation.

Schumacher et al. [104] studied the effect of $300 \mathrm{~mL}$ chicory coffee rich in caffeic acid given daily to 27 healthy volunteers for 1 week. They found that the whole blood and plasma viscosity were both significantly decreased. In another study, 20 healthy subjects daily consumed $7 \mathrm{~mL} / \mathrm{kg}$ of both red wine and purple grape juice for 14 days [104]. Platelet aggregation was inhibited and platelet-derived NO production increased, whereas the superoxide release decreased significantly [105]. In an intervention trial that lasts for 8 weeks, berry consumption resulted in favorable changes in platelet function, and antiplatelet activity was induced by both ADP and collagen [106]. Similar findings were also stated when consuming 2 or 3 kiwi fruits per day for 28 days [107]. The daily consumption of $50 \mathrm{~mL}$ of pomegranate juice ( $1.5 \mathrm{mmol}$ total polyphenols) for 2 weeks was found to reduce LDL susceptibility to aggregation and retention and to increase the activity of serum paraoxonase by $20 \%$ [108]. Data from several studies shows that the consumption of $100 \mathrm{mg}$ flavanols (equivalent to $11 \mathrm{~g}$ dark chocolate, $52 \mathrm{~g}$ milk chocolate, or 50 to $100 \mathrm{~mL}$ cocoa drink) also inhibits the collagen-epinephrine- and collagen-ADPinduced closure [109]. Hamed et al. [110] proved that the intake of dark chocolate (700 mg flavonoids/day) for a week significantly reduced ADP- and AA-induced platelet activation in addition to activated glycoprotein IIb/IIIa. Similar findings were reported by Rull et al. [111] who proved that dark chocolate (with high and low flavanol levels) supplementation for 6 weeks lowered platelet responsiveness to ADP and to thrombin receptor activator peptide. Furthermore, Wright et al. [112] found that both methylated and sulphated flavonoid metabolites have higher platelet inhibitory effects than the glucoronidated metabolites.

Conversely, in a study conducted on 20 subjects, a polyphenol-rich meal every lunchtime for 5 days had no ex vivo effect on platelet aggregation although the total plasma flavonoids significantly increased [113]. In the same way, a daily supplementation with $200 \mathrm{mg}$ of flavonoids from grape seeds had no effect on platelet aggregation in a doubleblind randomized study performed in male smokers [114]. Platelet aggregation did not evidence significant differences in 21 postmenopausal women supplemented with wine polyphenols [115]. Additionally, the daily intake of $2 \mathrm{~g}$ of cocoa flavonols in healthy volunteers during 12 weeks did not exert significant differences in platelet aggregation [116].

Taken together, these findings underline that further in vivo studies are absolutely required to confirm the potentiality of phenolic compounds as antiplatelet aggregation agents. This potentiality renders polyphenols an important dietary element in the prevention of CVD and possibly an alternative to pharmacological treatments of platelet aggregation.

\section{From Effects of Phenolic Compounds to Absorption and Bioavailability}

The bioavailability of polyphenols and related metabolites following oral intake has been viewed as a hot research topic in the last decades. Indeed, results obtained so far have indicated that the bioavailability of phenolic compounds is related to the cleavage and release of the aglycone by digestive enzymes and microbial fermentation, as shown in Figure 5 [117]. The identification of phenolic compounds in biological samples to check its bioavailability, metabolism, and intestinal absorption is very crucial. These metabolomic analyses are frequently done using nuclear magnetic resonance and mass spectrometry ([118]).

Lactase phlorizin hydrolase and cytosolic $\beta$-glucosidase were found to be the main digestive enzymes that hydrolyze phenolic glycosides and release the aglycones which enter the epithelial cells $[119,120]$. Before entering into the systemic circulation, polyphenolic aglycones undergo some degrees of phase II metabolism through the action of sulfotransferases, uridine- $5^{\prime}$-diphosphate glucuronosyl transferases, or catechol-O-methyltransferases [121]. On the other side, compounds with a high degree of polymerization are exposed to microbial catabolism in the colon before reaching the liver, where they can also be subjected to conjugation [122]. Also worthy of note is that the different compositions of the colonic microflora between individuals lead to variations in the released metabolites [123]. In contrast, some polyphenols show specific pharmacokinetic features, as their glycosides are considered to be more bioavailable than their aglycones. As an example, some anthocyanins, glycosides, and isoflavone-glycosides could be efficiently absorbed across the gastrointestinal mucosa $[124,125]$. For instance, Kay et al. [126] revealed that the absorption rate for quercetin glycosides is higher than that of the aglycones.

\section{Phenolic Compounds: Looking at Adverse Effects, Drug Interaction, and Related Toxicity}

The beneficial effects of phenolic compounds could be diminished by aspects as lifestyle, gender, age, genetic factors, underlying diseases, and interactions with conventional drugs, the latter being of great importance with regard to safety concerns. In fact, although the risk of adverse effects due to interactions between herbal medicinal products and conventional drugs is still an underexploited problem, some 


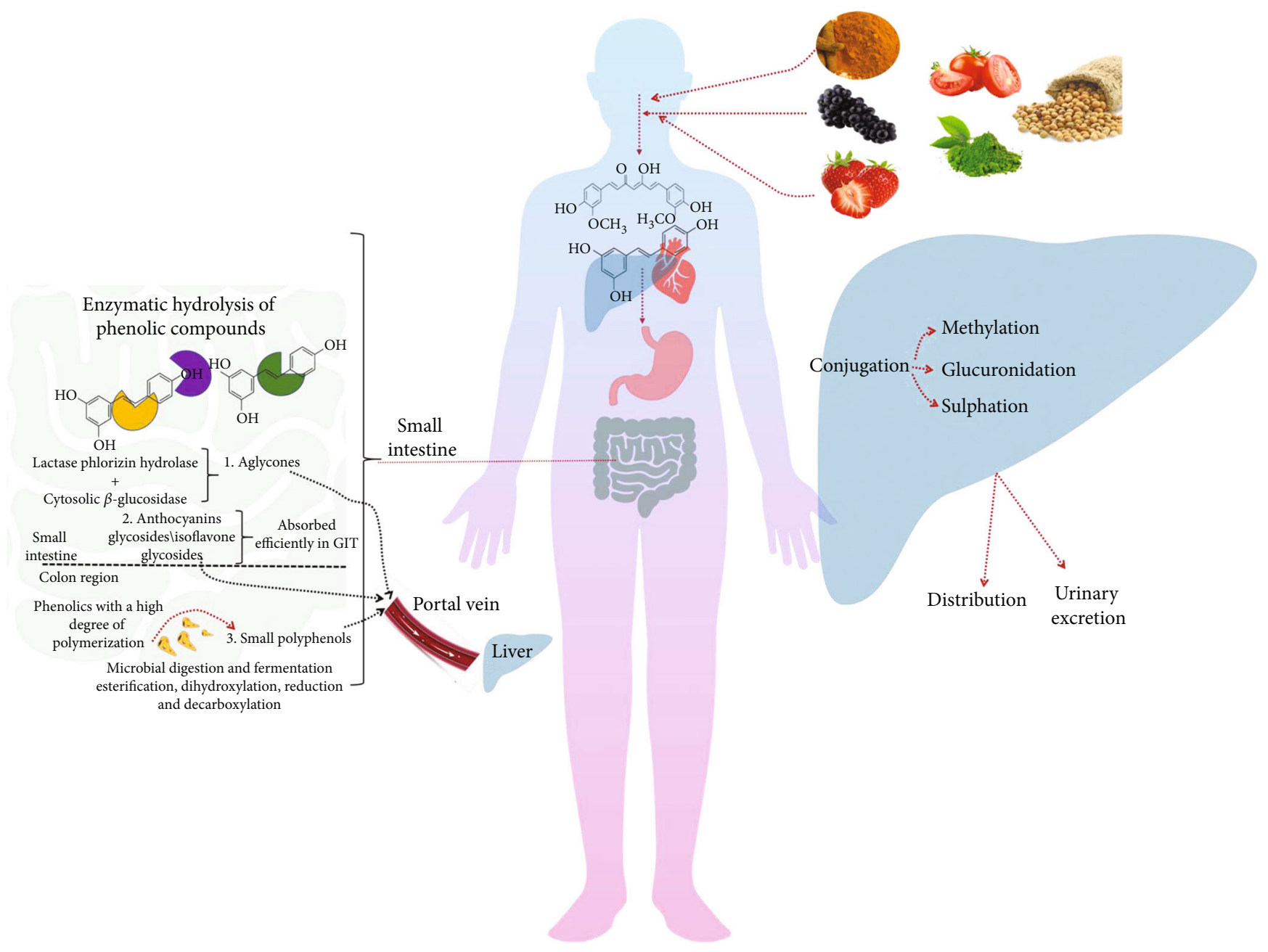

FIGURE 5: Absorption and bioavailability of phenolics as an antiplatelet agent through the liver distribution system.

studies highlighting concerns regarding antithrombotic agents have been reported [96, 127, 128]. Overall, it is clear that the majority of these works do not address a single/specific drug and, on the contrary, preferentially consider anticoagulant (e.g., warfarin) and antiplatelet (e.g., aspirin, clopidogrel, or ticlopidine) drugs [129] as the whole focus of the study (Table 1).

The most referred mechanisms in such interactions include inhibition of thromboxane synthesis and/or COX activity and interference in drug metabolism, which globally results in synergistic effects with drugs, and ultimately, promoting platelet inhibition and increasing the risk of bleeding in some patients $[127,129]$. Yet, in most cases, the mechanism of action is not deeply determined, and a great number of aspects on herbal-antiplatelet interactions remain unexplored. In addition, most of them lack the identification of the active compounds' class in such interactions, just referring to the name of the herbal product [130, 131]. Nevertheless, phenolic compounds of some herbal plants, such as Camellia sinensis (L.) Kuntze, Citrus paradisi Macfad., Crataegus spp., Curcuma longa L., Crocus sativus L., Foeniculum vulgare Mill. Ginkgo biloba L., Matricaria recutita L., and Vaccinium myrtillus L. have been pointed out as probable plant components capable of interacting with antithrombotic drugs.

\section{Paving the Way for Effective Clinical Applications}

Phenolic compounds are gaining a huge importance in the promotion, prevention, and maintenance of good health, as well as in the treatment of multiple diseases, because of their remarkable bioactive effects, with special emphasis on their antioxidant, antitumor, antihyperglycemic, cardioprotective, antithrombotic, vasodilatory, and anti-inflammatory activities. This wide range of activities makes such biomolecules of hot potential for both pharmaceutical and medical applications.

As stated, phenolic compounds are able to modulate some transcriptional factors (e.g., NF- $\kappa \mathrm{B}$ ) to regulate the expression of some proinflammatory cytokines (e.g., IL-1 $\beta$ and TNF- $\alpha$ ) and even enzymes (e.g., iNOS and COX-2) that are present in inflammatory processes. NF- $\kappa \mathrm{B}$ is associated with the Nrf-2 regulation that regulates the expression of anti-inflammatory enzymes [55, 56]. Considering such mechanisms and their ability to inhibit ROS, the 


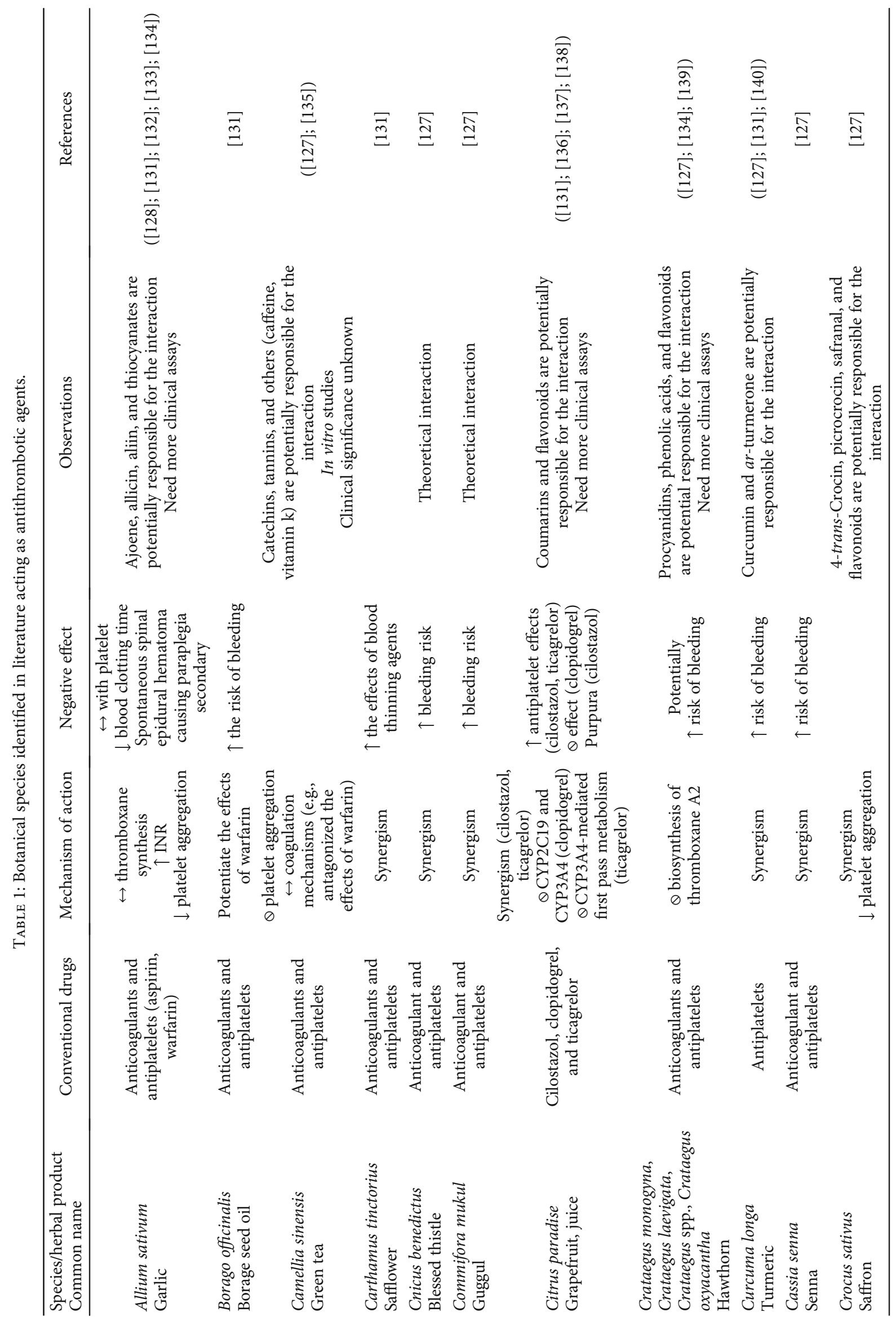




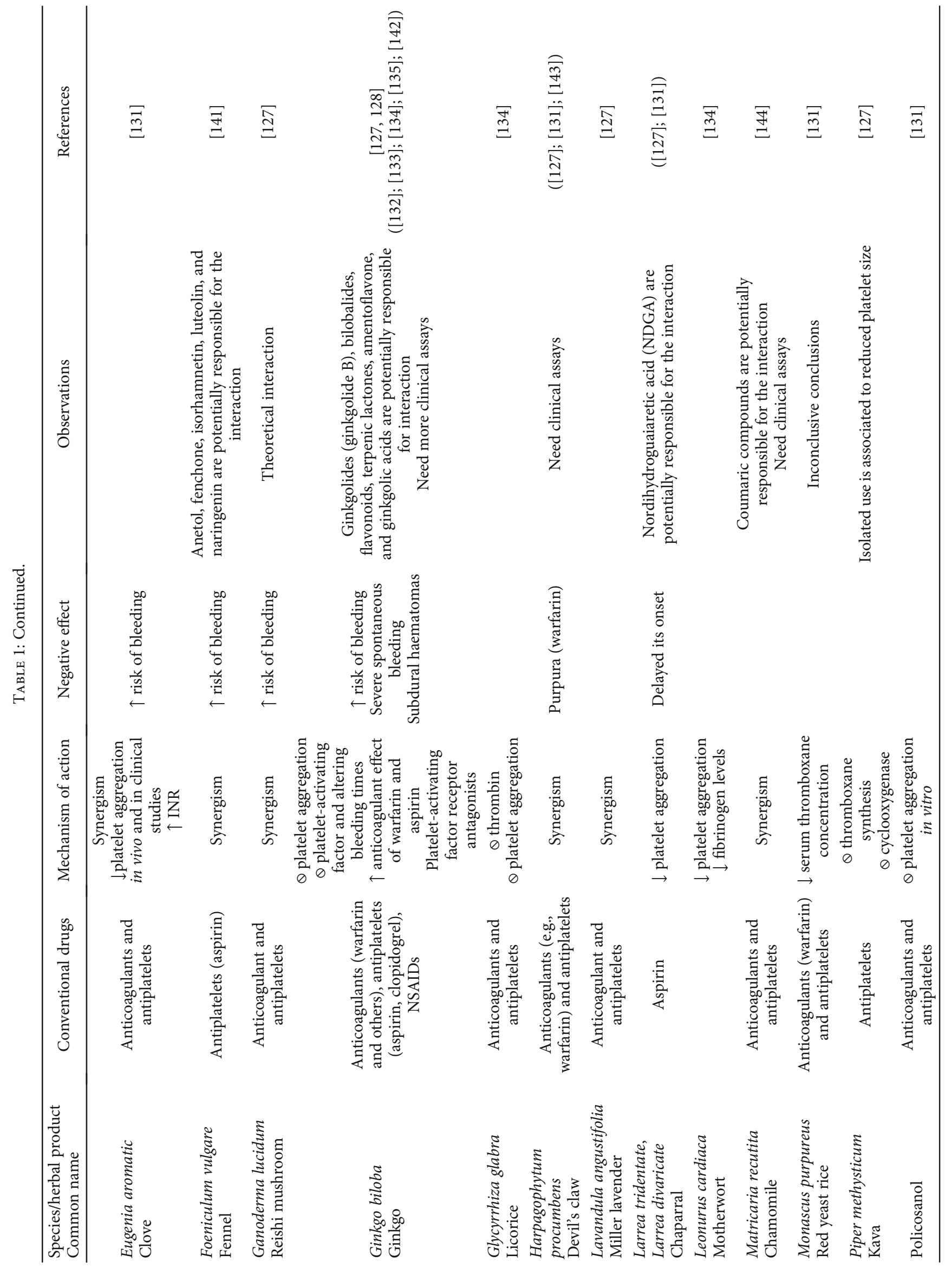




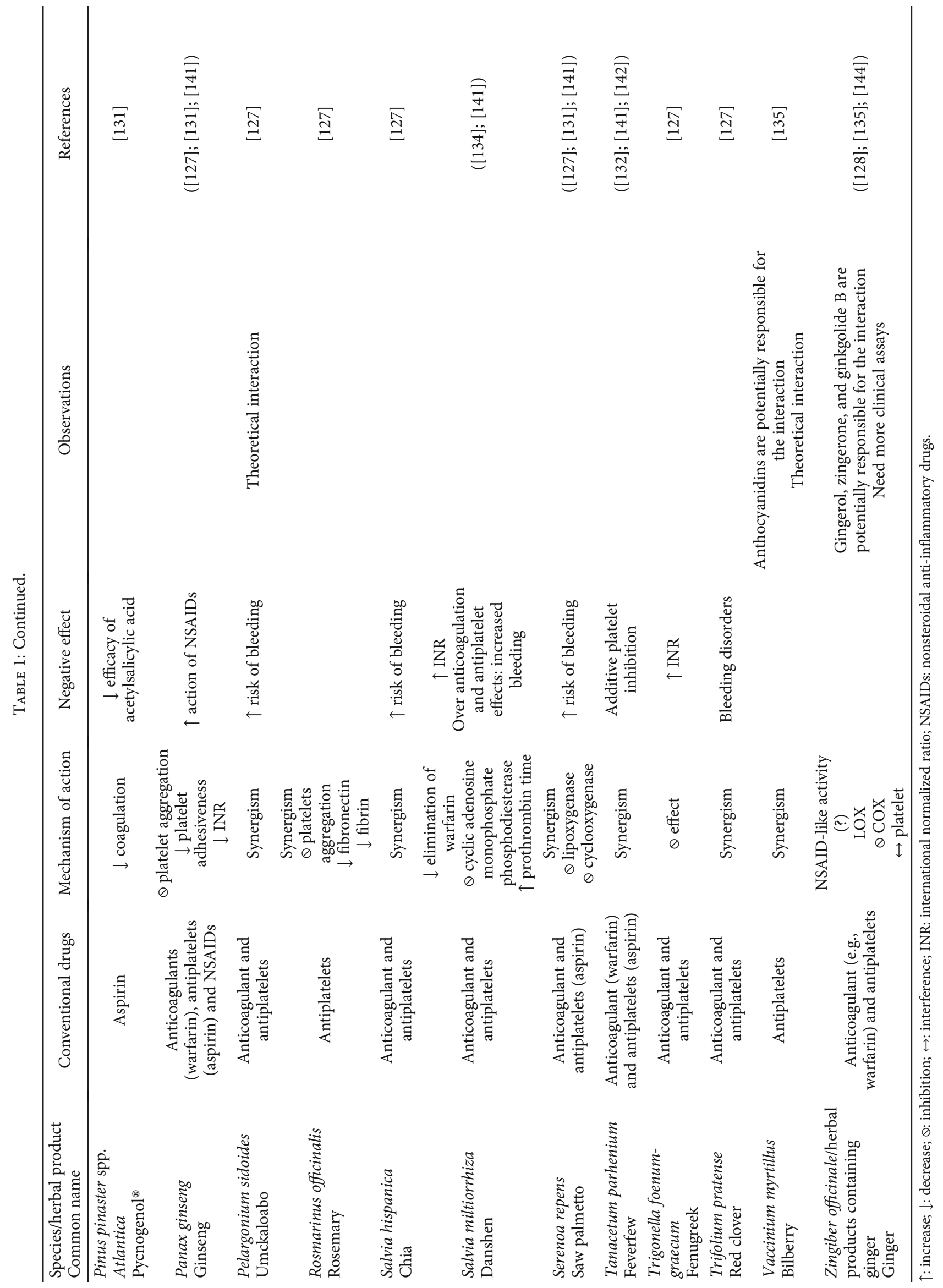


cardioprotective effects of such molecules are due to its ability to improve endothelial dysfunction in CHD [37], since it also increases the bioactivity of endothelial NO. Moreover, evidence has stated that flavonoids reverse endothelial dysfunction in addition to lowering blood pressure [36].

To name a few mechanisms, there is increasing in vitro evidence that shows that polyphenols reduce platelet NADPH oxidase activation $[83,84]$, ROS formation, thromboxane formation, AA pathway $[84,85]$, and platelet stimulation through $\mathrm{PI} 3 \mathrm{~K} / \mathrm{AKT}$ [91]. Nonetheless, there is still little in vivo evidence showing that polyphenols can inhibit platelet aggregation, increase NO production [105], inhibit ADP-induced platelet activity [106], and reduce AA-induced platelet activation [110]. So, there is no doubt that the in vitro data cannot be translated into the in vivo condition, because the molecules undergo biotransformation reactions that alter their bioavailability. As a consequence, this would lead to discrete and contradictory biological effects.

There is increasing evidence showing that the effectiveness of selective phenolic compounds is supported by their important role in whole foods, where when used in combination, such as through the intake of whole plant foods with a mixture of polyphenols, better antiplatelet effects are reached when compared to isolated compounds. For these reasons, further studies are needed to confirm its potential.

\section{Conclusions and Upcoming Perspectives}

Phenolic compounds have revealed several positive effects in CVD models in vitro and in vivo. However, for in vivo models, the evidence is scarce. However, with the described evidence, it can be affirmed that polyphenols are a key element in CVD prevention. Regarding the effectiveness of phenolic compounds, little has been studied about their interactions with medications, like anticoagulants and antiplatelets. Such interactions, that include mechanism of inhibition of the synthesis of thromboxane or COX activity, may increase the risk of bleeding in such patients, despite that there is a wide range of herbal products that interact with antithrombotic drugs in a synergistic manner.

Taken together, data presented here clearly underline the need for more in vivo studies and clinical trials to evaluate the phenolic compounds' potential and to guarantee their efficacy. Also, more investigations are desired on isolated or mixed phenolic compounds and their relationship with CVDs in order to elucidate their potential and success for both prevention and treatment. Finally, and not least important, as it is poorly described, is the design of more clinical trials, because most of the currently performed clinical studies with these herbal products lack identification and quantification of phenolic compounds.

\section{Data Availability}

The data used to support the findings of this study are available from the corresponding author upon request.

\section{Conflicts of Interest}

The authors declare no conflict of interest.

\section{Authors' Contributions}

J.S.-R., M.B., M.M., N.C.-M., and W.C.C. contributed to the study conception and design, acquisition of data, and the analysis and interpretation of data. C.Q., W.Z., M.K., S.M.C., O.R.P., A.O.A., O.A., A.C.M., J.Ž., F.N., S.A.A., F.K., M.F., I.C.B., R.V.B., M.M.A, literature review. J.S.-R., M.M., W.C.C., M.B., and N.C.-M. contributed to drafting the manuscript and critically revising the manuscript. All authors prepared the manuscript, contributed equally, and read and approved the final manuscript.

\section{Acknowledgments}

N.C.-M. acknowledges the Portuguese Foundation for Science and Technology under the Horizon 2020 Program (PTDC/PSI-GER/28076/2017). Illustrations used are licensed from http://stock.adobe.com

\section{References}

[1] M. W. H. Behan and R. F. Storey, "Antiplatelet therapy in cardiovascular disease," Postgraduate Medical Journal, vol. 80, no. 941, pp. 155-164, 2018.

[2] I. Figueira, A. Fernandes, A. Mladenovic Djordjevic et al., "Interventions for age-related diseases: shifting the paradigm," Mechanisms of Ageing and Development, vol. 160, pp. 69-92, 2016.

[3] M. El Haouari and J. A. Rosado, "Medicinal plants with antiplatelet activity," Phytotherapy Research, vol. 30, no. 7, pp. 1059-1071, 2016.

[4] B. Olas, "The multifunctionality of berries toward blood platelets and the role of berry phenolics in cardiovascular disorders," Platelets, vol. 28, no. 6, pp. 540-549, 2017.

[5] P. Sikka and V. K. Bindra, "Newer antithrombotic drugs," Indian journal of critical care medicine: peer-reviewed, official publication of Indian Society of Critical Care Medicine, vol. 14, no. 4, pp. 188-195, 2010.

[6] H. Khan, M. Jawad, M. A. Kamal et al., "Evidence and prospective of plant derived flavonoids as antiplatelet agents: strong candidates to be drugs of future," Food and Chemical Toxicology, vol. 119, pp. 355-367, 2018.

[7] A. Meshkini and M. Tahmasbi, "Antiplatelet aggregation activity of walnut hull extract via suppression of reactive oxygen species generation and caspase activation," Journal of Acupuncture and Meridian Studies, vol. 10, no. 3, pp. 193-203, 2017.

[8] D. J. Newman and G. M. Cragg, "Natural products as sources of new drugs over the nearly four decades from 01/1981 to 09/2019," Journal of Natural Products, vol. 83, no. 3, pp. 770-803, 2020.

[9] C. C. Tangney and H. E. Rasmussen, "Polyphenols, inflammation, and cardiovascular disease," Current atherosclerosis reports, vol. 15, no. 5, article 324, 2013.

[10] R. V. Giglio, A. M. Patti, A. F. G. Cicero et al., "Polyphenols: potential use in the prevention and treatment of cardiovascular diseases," Current Pharmaceutical Design, vol. 24, no. 2, pp. 239-258, 2018. 
[11] S. Khurana, K. Venkataraman, A. Hollingsworth, M. Piche, and T. C. Tai, "Polyphenols: benefits to the cardiovascular system in health and in aging," Nutrients, vol. 5, no. 10, pp. 3779-3827, 2013.

[12] M. Bijak, A. Sut, A. Kosiorek, J. Saluk-Bijak, and J. Golanski, "Dual anticoagulant/antiplatelet activity of polyphenolic grape seeds extract," Nutrients, vol. 11, no. 1, p. 93, 2019.

[13] G. Hirsch, P. R. Nazario Viecili, A. S. de Almeida et al., "Natural products with antiplatelet action," Current Pharmaceutical Design, vol. 23, no. 8, pp. 1228-1246, 2017.

[14] M. Lutz, E. Fuentes, F. Ávila, M. Alarcón, and I. Palomo, "Roles of phenolic compounds in the reduction of risk factors of cardiovascular diseases," Molecules, vol. 24, no. 2, 2019.

[15] G. V. de Oliveira, M. Volino-Souza, C. A. Conte-Júnior, and T. S. Alvares, "Food-derived polyphenol compounds and cardiovascular health: A nano- technological perspective," Food Bioscience, vol. 41, article 101033, 2021.

[16] G. R. Velderrain-Rodríguez, H. Palafox-Carlos, A. WallMedrano et al., "Phenolic compounds: their journey after intake," Food \& Function, vol. 5, no. 2, pp. 189-197, 2014.

[17] V. Lattanzio, "Phenolic compounds: introduction," in Natural Products: Phytochemistry, Botany and Metabolism of Alkaloids, Phenolics and Terpenes, K. G. Ramawat and J.-M. Mérillon, Eds., pp. 1543-1580, Springer Berlin Heidelberg, Berlin, Heidelberg, 2013.

[18] K. Min, C. Freeman, H. Kang, and S.-U. Choi, “The regulation by phenolic compounds of soil organic matter dynamics under a changing environment," BioMed Research International, vol. 2015, Article ID 825098, 11 pages, 2015.

[19] M. Vidovic, F. Morina, S. Milić Komić, and S. VeljovicJovanovic, "An improved HPLC-DAD method for simultaneously measuring phenolics in the leaves of Tilia platyphyllos and Ailanthus altissima," Botanica Serbica, vol. 39, pp. 177186, 2015.

[20] R. C. P. S. Reinaldo, A. C. P. Santiago, P. M. Medeiros, and U. P. Albuquerque, "Do ferns and lycophytes function as medicinal plants? A study of their low representation in traditional pharmacopoeias," Journal of Ethnopharmacology, vol. 175, pp. 39-47, 2015.

[21] M. Działo, J. Mierziak, U. Korzun, M. Preisner, J. Szopa, and A. Kulma, "The potential of plant phenolics in prevention and therapy of skin disorders," International journal of molecular sciences, vol. 17, no. 2, p. 160, 2016.

[22] X.-H. Meng, C. Liu, R. Fan et al., "Antioxidative flavan-3-ol dimers from the leaves of Camellia fangchengensis," Journal of Agricultural and Food Chemistry, vol. 66, no. 1, pp. 247254, 2017.

[23] R. Touati, S. A. O. Santos, S. M. Rocha, K. Belhamel, and A. J. D. Silvestre, "The potential of cork from Quercus suber L. grown in Algeria as a source of bioactive lipophilic and phenolic compounds," Industrial Crops and Products, vol. 76, pp. 936-945, 2015.

[24] D. Ravishankar, A. K. Rajora, F. Greco, and H. M. I. Osborn, "Flavonoids as prospective compounds for anti-cancer therapy," The International Journal of Biochemistry \& Cell Biology, vol. 45, no. 12, pp. 2821-2831, 2013.

[25] E. Alissa and G. Ferns, "Functional foods and nutraceuticals in the primary prevention of cardiovascular diseases," Journal of nutrition and metabolism, vol. 2012, Article ID 569486, 16 pages, 2012.
[26] T. W. George, C. Niwat, S. Waroonphan, M. H. Gordon, and J. A. Lovegrove, "Effects of chronic and acute consumption of fruit- and vegetable-puree-based drinks on vasodilation, risk factors for CVD and the response as a result of theeNOSG298T polymorphism," Proceedings of the Nutrition Society, vol. 68, no. 2, pp. 148-161, 2009.

[27] R. H. Liu, "Health benefits of fruit and vegetables are from additive and synergistic combinations of phytochemicals," The American Journal of Clinical Nutrition, vol. 78, no. 3, pp. 517S-520S, 2003.

[28] T. Maraldi, D. Vauzour, and C. Angeloni, "Dietary polyphenols and their effects on cell biochemistry and pathophysiology 2013," Oxidative Medicine and Cellular Longevity, vol. 2014, Article ID 576363, 3 pages, 2014.

[29] J. Tomé-Carneiro and F. Visioli, "Polyphenol-based nutraceuticals for the prevention and treatment of cardiovascular disease: review of human evidence," Phytomedicine, vol. 23, no. 11, pp. 1145-1174, 2016.

[30] O. D. Rangel-Huerta, B. Pastor-Villaescusa, C. M. Aguilera, and A. Gil, "A systematic review of the efficacy of bioactive compounds in cardiovascular disease: phenolic compounds," Nutrients, vol. 7, no. 7, pp. 5177-5216, 2015.

[31] K. S. Bhullar, G. Lassalle-Claux, M. Touaibia, and H. P. V. Rupasinghe, "Antihypertensive effect of caffeic acid and its analogs through dual renin- angiotensin-aldosterone system inhibition," European Journal of Pharmacology, vol. 730, pp. 125-132, 2014.

[32] T. K. W. Ma, K. K. H. Kam, B. P. Yan, and Y.-Y. Lam, "Reninangiotensin-aldosterone system blockade for cardiovascular diseases: current status," British journal of pharmacology, vol. 160, no. 6, pp. 1273-1292, 2010.

[33] H. Peng, O. A. Carretero, N. Vuljaj et al., "Angiotensin-converting enzyme inhibitors: a new mechanism of action," Circulation, vol. 112, no. 16, pp. 2436-2445, 2005.

[34] A. O. Ademiluyi and G. Oboh, "Angiotensin I-converting enzyme inhibitory activity and hypocholesterolemic effect of some fermented tropical legumes in streptozotocininduced diabetic rats," International Journal of Diabetes in Developing Countries, vol. 35, no. 4, pp. 493-500, 2015.

[35] A. O. Ademiluyi and G. Oboh, "Soybean phenolic-rich extracts inhibit key-enzymes linked to type 2 diabetes $(\alpha$ amylase and $\alpha$-glucosidase) and hypertension (angiotensin I converting enzyme) in vitro," Experimental and Toxicologic Pathology, vol. 65, no. 3, pp. 305-309, 2013.

[36] D. Grassi, G. Desideri, P. Di Giosia, P. Cheli, M. Dibiase, and C. Ferri, "Flavonoids and renin-angiotensin-aldosterone system modulation: cocoa flavanols and blood pressure," Agro Food Industry Hi-Tech, vol. 22, pp. 14-17, 2011.

[37] S. J. Duffy and J. A. Vita, "Effects of phenolics on vascular endothelial function," Current Opinion in Lipidology, vol. 14, no. 1, pp. 21-27, 2003.

[38] R.-M. Valls, M. Farràs, M. Suárez et al., "Effects of functional olive oil enriched with its own phenolic compounds on endothelial function in hypertensive patients. A randomised controlled trial," Food Chemistry, vol. 167, pp. 30-35, 2015.

[39] J. Dai and R. J. Mumper, "Plant phenolics: extraction, analysis and their antioxidant and anticancer properties," Molecules, vol. 15, no. 10, pp. 7313-7352, 2010.

[40] M. S. Fernandez-Panchon, D. Villano, A. M. Troncoso, and M. C. Garcia-Parrilla, "Antioxidant activity of phenolic compounds: from in vitro results to in vivo evidence," Critical 
Reviews in Food Science and Nutrition, vol. 48, no. 7, pp. 649$671,2008$.

[41] A. Mishra, A. K. Sharma, S. Kumar, A. K. Saxena, and A. K. Pandey, "Bauhinia variegata leaf extracts exhibit considerable antibacterial, antioxidant, and anticancer activities," BioMed Research International, vol. 2013, Article ID 915436, 10 pages, 2013.

[42] A. K. Pandey and A. Mishra, "Antifungal and antioxidative potential of oil and extracts derived from leaves of Indian spice plant Cinnamomum tamala," Cellular and molecular biology (Noisy-le-Grand, France), vol. 58, pp. 142-147, 2012.

[43] V. J. Thannickal and B. L. Fanburg, "Reactive oxygen species in cell signaling," American Journal of Physiology-Lung Cellular and Molecular Physiology, vol. 279, no. 6, pp. L1005L1028, 2000.

[44] V. Stangl, H. Dreger, K. Stangl, and M. Lorenz, "Molecular targets of tea polyphenols in the cardiovascular system," Cardiovascular research, vol. 73, no. 2, pp. 348-358, 2007.

[45] F. Tosetti, D. M. Noonan, and A. Albini, "Metabolic regulation and redox activity as mechanisms for angioprevention by dietary phytochemicals," International Journal of Cancer, vol. 125, no. 9, pp. 1997-2003, 2009.

[46] S. Upadhyay and M. Dixit, "Role of polyphenols and other phytochemicals on molecular signaling," Oxidative Medicine and Cellular Longevity, vol. 2015, Article ID 504253, 15 pages, 2015.

[47] G. Mann, D. Rowlands, F. Li, P. Dewinter, and R. Siow, “Activation of endothelial nitric oxide synthase by dietary isoflavones: role of NO in Nrf2-mediated antioxidant gene expression," Cardiovascular research, vol. 75, no. 2, pp. 261-274, 2007.

[48] Z. Ungvari, Z. Bagi, A. Feher et al., "Resveratrol confers endothelial protection via activation of the antioxidant transcription factor Nrf2," American journal of physiology Heart and circulatory physiology, vol. 299, no. 1, pp. H18-H24, 2010.

[49] Y. Steffen, C. Gruber, T. Schewe, and H. Sies, "Mono- O -methylated flavanols and other flavonoids as inhibitors of endothelial NADPH oxidase," Archives of Biochemistry and Biophysics, vol. 469, no. 2, pp. 209-219, 2008.

[50] L. K. Leung, Y. Su, R. Chen, Z. Zhang, Y. Huang, and Z.-Y. Chen, "Theaflavins in black tea and catechins in green tea are equally effective antioxidants," The Journal of Nutrition, vol. 131, no. 9, pp. 2248-2251, 2001.

[51] P. Anandh Babu and D. Liu, "Green tea catechins and cardiovascular health: an update," Current Medicinal Chemistry, vol. 15, no. 18, pp. 1840-1850, 2008.

[52] J. Terao, "Dietary flavonoids as antioxidants," Forum of Nutrition, vol. 61, pp. 87-94, 2009.

[53] K. L. Rock and H. Kono, "The inflammatory response to cell death," Annual Review of Pathology, vol. 3, no. 1, pp. 99-126, 2008.

[54] J. Lago, A. Toledo-Arruda, M. Mernak et al., "Structure-activity association of flavonoids in lung diseases," Molecules, vol. 19, no. 3, 2008.

[55] J. C. Maroon, J. W. Bost, and A. Maroon, "Natural antiinflammatory agents for pain relief," Surgical Neurology International, vol. 1, pp. 80-80, 2008.

[56] O. Taofiq, A. Martins, M. F. Barreiro, and I. C. F. R. Ferreira, "Anti-inflammatory potential of mushroom extracts and isolated metabolites," Trends in Food Science \& Technology, vol. 50, pp. 193-210, 2016.
[57] R. Korhonen, A. Lahti, H. Kankaanranta, and E. Moilanen, "Nitric oxide production and signaling in inflammation," Current Drug Targets - Inflammation \& Allergy, vol. 4, no. 4, pp. 471-479, 2005.

[58] M.-J. Bak, V. L. Truong, H.-S. Kang, M. Jun, and W.-S. Jeong, "Anti-inflammatory effect of procyanidins from wild grape (Vitis amurensis) seeds in LPS-induced RAW 264.7 cells," Oxidative Medicine and Cellular Longevity, vol. 2013, Article ID 409321, 11 pages, 2013.

[59] Y. Shan, R. Zhao, W. Geng et al., "Protective effect of sulforaphane on human vascular endothelial cells against lipopolysaccharide-induced inflammatory damage," Cardiovascular Toxicology, vol. 10, no. 2, pp. 139-145, 2010.

[60] B.-T. Chen, W.-X. Li, R.-R. He et al., "Anti-inflammatory effects of a polyphenols-rich extract from tea (Camellia sinensis) flowers in acute and chronic mice models," Oxidative Medicine and Cellular Longevity, vol. 2012, Article ID 537923, 7 pages, 2012.

[61] J. Miranda, A. Lasa, L. Aguirre, A. Fernandez-Quintela, I. Milton, and M. P. Portillo, "Potential application of nonflavonoid phenolics in diabetes: antiinflammatory effects," Current Medicinal Chemistry, vol. 22, no. 1, pp. 112-131, 2014.

[62] C. Rius, M. Abu-Taha, C. Hermenegildo et al., "Trans- but NotCis-Resveratrol impairs angiotensin-II-mediated vascular inflammation through inhibition of NF- $\kappa \mathrm{B}$ activation and peroxisome proliferator-activated Receptor- $\gamma$ upregulation," The Journal of Immunology, vol. 185, no. 6, pp. 37183727, 2010.

[63] Y.-H. Deng, D. Alex, H.-Q. Huang et al., "Inhibition of TNF$\alpha$-mediated endothelial cell-monocyte cell adhesion and adhesion molecules expression by the resveratrol derivative, trans-3,5,4'-trimethoxystilbene," Phytotherapy Research, vol. 25, no. 3, pp. 451-457, 2011.

[64] L. Dugo, M. G. Belluomo, C. Fanali et al., "Effect of cocoa polyphenolic extract on macrophage polarization from proinflammatory M1 to anti-inflammatory M2 state," Oxidative Medicine and Cellular Longevity, vol. 2017, Article ID 6293740, 11 pages, 2017.

[65] C. Santangelo, R. Vari, B. Scazzocchio, R. Di Benedetto, C. Filesi, and R. Masella, "Polyphenols, intracellular signalling and inflammation," Annali-Istituto Superiore Di Sanita, vol. 43, no. 4, pp. 394-405, 2007.

[66] C. L. Léger, M. A. Carbonneau, F. Michel et al., "A thromboxane effect of a hydroxytyrosol-rich olive oil wastewater extract in patients with uncomplicated type I diabetes," European Journal of Clinical Nutrition, vol. 59, no. 5, pp. 727-730, 2005.

[67] M. Crescente, G. Jessen, S. Momi et al., "Interactions of gallic acid, resveratrol, quercetin and aspirin at the platelet cyclooxygenase-1 level. Functional and modelling studies," Thrombosis and Haemostasis, vol. 102, no. 8, pp. 336-346, 2009.

[68] A. Nemmar, D. Subramaniyan, and B. H. Ali, "Protective effect of curcumin on pulmonary and cardiovascular effects induced by repeated exposure to diesel exhaust particles in mice," PloS One, vol. 7, no. 6, article e39554, 2012.

[69] N. Vallianou, C. Tsang, M. Taghizadeh, A. Davoodvandi, and S. Jafarnejad, "Effect of cinnamon (Cinnamomum Zeylanicum) supplementation on serum C-reactive protein concentrations: A meta-analysis and systematic review," Complementary Therapies in Medicine, vol. 42, pp. 271278, 2019. 
[70] M. Moballegh Nasery, B. Abadi, D. Poormoghadam et al., "Curcumin delivery mediated by bio-based nanoparticles: a review," Molecules, vol. 25, no. 3, p. 689, 2020.

[71] R. Andriantsitohaina, C. Auger, T. Chataigneau et al., "Molecular mechanisms of the cardiovascular protective effects of polyphenols," British Journal of Nutrition, vol. 108, no. 9, pp. 1532-1549, 2012.

[72] B. Dasgupta and J. Milbrandt, "Resveratrol stimulates AMP kinase activity in neurons," Proceedings of the National Academy of Sciences of the United States of America, vol. 104, no. 17, pp. 7217-7222, 2007.

[73] X. Hou, D. Rooklin, H. Fang, and Y. Zhang, "Resveratrol serves as a protein-substrate interaction stabilizer in human SIRT1 activation," Scientific Reports, vol. 6, no. 1, p. 38186, 2016.

[74] F. Lan, J. M. Cacicedo, N. Ruderman, and Y. Ido, "SIRT1 Modulation of the Acetylation Status, Cytosolic Localization, and Activity of LKB1:," The Journal of Biological Chemistry, vol. 283, no. 41, pp. 27628-27635, 2008.

[75] G. Suchankova, L. E. Nelson, Z. Gerhart-Hines et al., "Concurrent regulation of AMP-activated protein kinase and SIRT1 in mammalian cells," Biochemical and Biophysical Research Communications, vol. 378, no. 4, pp. 836-841, 2009.

[76] Z. Chen, I. C. Peng, X. Cui, Y.-S. Li, S. Chien, and J. Y. J. Shyy, "Shear stress, SIRT1, and vascular homeostasis," Proceedings of the National Academy of Sciences of the United States of America, vol. 107, no. 22, pp. 10268-10273, 2010.

[77] M. Chalopin, A. Tesse, M. C. Martínez, D. Rognan, J.F. Arnal, and R. Andriantsitohaina, "Estrogen receptor alpha as a key target of red wine polyphenols action on the endothelium," PloS One, vol. 5, no. 1, article e8554, 2010.

[78] M. Cipolletti, V. Solar Fernandez, E. Montalesi, M. Marino, and M. Fiocchetti, "Beyond the antioxidant activity of dietary polyphenols in cancer: the modulation of estrogen receptors (ERs) signaling," International journal of molecular sciences, vol. 19, no. 9, 2018.

[79] G. Davì and C. Patrono, "Platelet activation and atherothrombosis," New England Journal of Medicine, vol. 357, no. 24, pp. 2482-2494, 2007.

[80] F. Natella, M. Nardini, F. Virgili, and C. Scaccini, "Role of dietary polyphenols in the platelet aggregation network-a review of the in vitro studies," Current Topics in Nutraceutical Research, vol. 4, pp. 2-21, 2007.

[81] C. Faggio, A. Sureda, S. Morabito et al., "Flavonoids and platelet aggregation: a brief review," European Journal of Pharmacology, vol. 807, pp. 91-101, 2017.

[82] P. Pignatelli, F. M. Pulcinelli, A. Celestini et al., "The flavonoids quercetin and catechin synergistically inhibit platelet function by antagonizing the intracellular production of hydrogen peroxide," The American Journal of Clinical Nutrition, vol. 72, no. 5, pp. 1150-1155, 2000.

[83] S. B. Wang, J. Y. Jang, Y. H. Chae et al., "Kaempferol suppresses collagen-induced platelet activation by inhibiting NADPH oxidase and protecting SHP-2 from oxidative inactivation," Free Radical Biology and Medicine, vol. 83, pp. 41-53, 2015.

[84] R. Carnevale, L. Loffredo, P. Pignatelli et al., "Dark chocolate inhibits platelet isoprostanes via NOX2 down-regulation in smokers," Journal of Thrombosis and Haemostasis, vol. 10, no. 1, pp. 125-132, 2012.

[85] J. A. Guerrero, M. L. Lozano, J. Castillo, O. Benavente-Garcia, V. Vicente, and J. Rivera, "Flavonoids inhibit platelet func- tion through binding to the thromboxane A2 receptor," Journal of Thrombosis and Haemostasis, vol. 3, no. 2, pp. 369-376, 2005.

[86] S. Mosawy, D. E. Jackson, O. L. Woodman, and M. D. Linden, "Inhibition of platelet-mediated arterial thrombosis and platelet granule exocytosis by $3^{\prime}, 4^{\prime}$-dihydroxyflavonol and quercetin," Platelets, vol. 24, no. 8, pp. 594-604, 2013.

[87] L. Navarro-Núñez, J. Rivera, J. A. Guerrero, C. Martínez, V. Vicente, and M. L. Lozano, "Differential effects of quercetin, apigenin and genistein on signalling pathways of protease-activated receptors $\operatorname{PAR}(1)$ and $\mathrm{PAR}(4)$ in platelets," British Journal of Pharmacology, vol. 158, no. 6, pp. 1548-1556, 2009.

[88] D.-J. Son, M.-R. Cho, Y.-R. Jin et al., "Antiplatelet effect of green tea catechins: a possible mechanism through arachidonic acid pathway," Prostaglandins, Leukotrienes and Essential Fatty Acids, vol. 71, no. 1, pp. 25-31, 2004.

[89] G. Hsiao, C.-Y. Chang, M.-Y. Shen et al., " $\alpha$-Naphthoflavone, a potent antiplatelet flavonoid, is mediated through inhibition of phospholipase $\mathrm{c}$ activity and stimulation of cyclic GMP formation," Journal of Agricultural and Food Chemistry, vol. 53, no. 13, pp. 5179-5186, 2005.

[90] J.-R. Sheu, G. Hsiao, P.-H. Chou, M.-Y. Shen, and D.-S. Chou, "Mechanisms involved in the antiplatelet activity of rutin, a glycoside of the flavonol quercetin, in human platelets," Journal of Agricultural and Food Chemistry, vol. 52, no. 14, pp. 4414-4418, 2004.

[91] L. Navarro-Núñez, M. L. Lozano, C. Martínez, V. Vicente, and J. Rivera, "Effect of quercetin on platelet spreading on collagen and fibrinogen and on multiple platelet kinases," Fitoterapia, vol. 81, no. 2, pp. 75-80, 2010.

[92] X. Tian, L. Chang, G. Ma et al., "Delineation of platelet activation pathway of scutellarein revealed its intracellular target as protein kinase C," Biological and Pharmaceutical Bulletin, vol. 39, no. 2, pp. 181-191, 2016.

[93] D. A. Calderwood, "Integrin activation," Journal of Cell Science, vol. 117, no. 5, pp. 657-666, 2004.

[94] P. Pignatelli, S. Di Santo, B. Buchetti, V. Sanguigni, A. Brunelli, and F. Violi, "Polyphenols enhance platelet nitric oxide by inhibiting protein kinase C-dependent NADPH oxidase activation: effect on platelet recruitment," The FASEB Journal, vol. 20, no. 8, pp. 1082-1089, 2006.

[95] F. Rubio-Senent, B. de Roos, G. Duthie, J. Fernández-Bolaños, and G. Rodríguez-Gutiérrez, "Inhibitory and synergistic effects of natural olive phenols on human platelet aggregation and lipid peroxidation of microsomes from vitamin Edeficient rats," European Journal of Nutrition, vol. 54, no. 8, pp. 1287-1295, 2015.

[96] B. Wright, J. P. E. Spencer, J. A. Lovegrove, and J. M. Gibbins, "Insights into dietary flavonoids as molecular templates for the design of anti-platelet drugs," Cardiovascular Research, vol. 97, pp. 13-22, 2015.

[97] G. P. Hubbard, J. M. Stevens, M. Cicmil et al., "Quercetin inhibits collagen-stimulated platelet activation through inhibition of multiple components of the glycoprotein VI signaling pathway," Journal of Thrombosis and Haemostasis, vol. 1, no. 5, pp. 1079-1088, 2003.

[98] D. Ravishankar, M. Salamah, A. Akimbaev et al., "Impact of specific functional groups in flavonoids on the modulation of platelet activation," Scientific Reports, vol. 8, no. 1, 2018. 
[99] M. Bojić, Z. Debeljak, M. Tomičić, M. Medić-Šarić, and S. Tomić, "Evaluation of antiaggregatory activity of flavonoid aglycone series," Nutrition Journal, vol. 10, no. 1, 2011.

[100] G. Lill, S. Voit, K. Schrör, and A.-A. Weber, "Complex effects of different green tea catechins on human platelets," FEBS Letters, vol. 546, no. 2-3, pp. 265-270, 2003.

[101] J. A. Ross and C. M. Kasum, "DIETARYFLAVONOIDS: bioavailability, metabolic effects, and safety," Annual Review of Nutrition, vol. 22, no. 1, pp. 19-34, 2002.

[102] L. M. Ostertag, N. O'Kennedy, G. W. Horgan, P. A. Kroon, G. G. Duthie, and B. de Roos, "In vitro anti-platelet effects of simple plant-derived phenolic compounds are only found at high, non-physiological concentrations," Molecular Nutrition \& Food Research, vol. 55, no. 11, pp. 1624-1636, 2011.

[103] R. Schmatz, T. R. Mann, R. Spanevello et al., "Moderate red wine and grape juice consumption modulates the hydrolysis of the adenine nucleotides and decreases platelet aggregation in streptozotocin-induced diabetic rats," Cell Biochemistry and Biophysics, vol. 65, no. 2, pp. 129-143, 2013.

[104] E. Schumacher, É. Vigh, V. Molnár et al., "Thrombosis preventive potential of chicory coffee consumption: a clinical study," Phytotherapy Research, vol. 25, no. 5, pp. 744-748, 2011.

[105] J. E. Freedman, C. Parker, L. Li et al., "Select flavonoids and whole juice from purple grapes inhibit platelet function and enhance nitric oxide release," Circulation, vol. 103, no. 23, pp. 2792-2798, 2001.

[106] I. Erlund, R. Koli, G. Alfthan et al., "Favorable effects of berry consumption on platelet function, blood pressure, and HDL cholesterol," The American Journal of Clinical Nutrition, vol. 87, no. 2, pp. 323-331, 2008.

[107] A. K. Duttaroy and A. Jørgensen, "Effects of kiwi fruit consumption on platelet aggregation and plasma lipids in healthy human volunteers," Platelets, vol. 15, no. 5, pp. 287-292, 2004.

[108] M. Aviram, L. Dornfeld, M. Rosenblat et al., "Pomegranate juice consumption reduces oxidative stress, atherogenic modifications to LDL, and platelet aggregation: studies in humans and in atherosclerotic apolipoprotein E-deficient mice," The American Journal of Clinical Nutrition, vol. 71, no. 5, pp. 1062-1076, 2000.

[109] L. M. Ostertag, N. O'Kennedy, P. A. Kroon, G. G. Duthie, and B. de Roos, "Impact of dietary polyphenols on human platelet function-a critical review of controlled dietary intervention studies," Molecular Nutrition \& Food Research, vol. 54, no. 1, pp. 60-81, 2010.

[110] M. Hamed, S. Gambert, K. Bliden et al., "Dark chocolate effect on platelet activity, C-reactive protein and lipid profile: a pilot study," Southern Medical Journal, vol. 101, no. 12, pp. 1203-1208, 2008.

[111] G. Rull, Z. N. Mohd-Zain, J. Shiel et al., "Effects of high flavanol dark chocolate on cardiovascular function and platelet aggregation,” Vascular Pharmacology, vol. 71, pp. 70-78, 2015.

[112] B. Wright, L. A. Moraes, C. F. Kemp et al., "A structural basis for the inhibition of collagen-stimulated platelet function by quercetin and structurally related flavonoids," British Journal of Pharmacology, vol. 159, no. 6, pp. 1312-1325, 2010.

[113] G. P. Hubbard, S. Wolffram, J. A. Lovegrove, and J. M. Gibbins, "The role of polyphenolic compounds in the diet as inhibitors of platelet function," Proceedings of the Nutrition Society, vol. 62, no. 2, pp. 469-478, 2003.
[114] A. R. Weseler, E. J. B. Ruijters, M.-J. Drittij-Reijnders, K. D. Reesink, G. R. M. M. Haenen, and A. Bast, "Pleiotropic benefit of monomeric and oligomeric flavanols on vascular health - a randomized controlled clinical pilot study," PloS One, vol. 6, no. 12, article e28460, 2011.

[115] L. Giovannelli, V. Pitozzi, C. Luceri et al., "Effects of dealcoholised wines with different polyphenol content on DNA oxidative damage, gene expression of peripheral lymphocytes, and haemorheology: an intervention study in post-menopausal women," European Journal of Nutrition, vol. 50, no. 1, pp. 19-29, 2011.

[116] J. I. Ottaviani, M. Balz, J. Kimball et al., "Safety and efficacy of cocoa flavanol intake in healthy adults: a randomized, controlled, double-masked trial," The American Journal of Clinical Nutrition, vol. 102, no. 6, pp. 1425-1435, 2015.

[117] H. Teng and L. Chen, "Polyphenols and bioavailability: an update," Critical Reviews in Food Science and Nutrition, vol. 59, no. 13, pp. 2040-2051, 2019.

[118] A. López-Yerena, I. Domínguez-López, A. Vallverdú-Queralt et al., "Metabolomics technologies for the identification and quantification of dietary phenolic compound metabolites: an overview," Antioxidants, vol. 10, no. 6, p. 846, 2021.

[119] E. T. Danielsen and E. M. Danielsen, "Glycol chitosan: a stabilizer of lipid rafts in the intestinal brush border," Biochimica et Biophysica Acta (BBA) - Biomembranes, vol. 1859, no. 3, pp. 360-367, 2017.

[120] S. Dudonné, P. Dubé, G. Pilon et al., "Modulation of strawberry/cranberry phenolic compounds glucuronidation by co-supplementation with onion: characterization of phenolic metabolites in rat plasma using an optimized $\mu$ SPE-UHPLCMS/MS method," Journal of Agricultural and Food Chemistry, vol. 62, no. 14, pp. 3244-3256, 2014.

[121] M. Margalef, Z. Pons, L. Iglesias-Carres, F. I. Bravo, B. Muguerza, and A. Arola-Arnal, "Flavanol plasma bioavailability is affected by metabolic syndrome in rats," Food Chemistry, vol. 231, pp. 287-294, 2017.

[122] G. Aragonès, F. Danesi, D. Del Rio, and P. Mena, "The importance of studying cell metabolism when testing the bioactivity of phenolic compounds," Trends in Food Science \& Technology, vol. 69, pp. 230-242, 2017.

[123] M. D'Archivio, C. Filesi, R. Di Benedetto, R. Gargiulo, C. Giovannini, and R. Masella, "Polyphenols, dietary sources and bioavailability," Annali-Istituto Superiore di Sanita, vol. 43, no. 4, pp. 348-361, 2007.

[124] J. Fang, "Some anthocyanins could be efficiently absorbed across the gastrointestinal mucosa: extensive presystemic metabolism reduces apparent bioavailability," Journal of Agricultural and Food Chemistry, vol. 62, no. 18, pp. 39043911, 2014.

[125] M. Monagas, M. Urpi-Sarda, F. Sánchez-Patán et al., "Insights into the metabolism and microbial biotransformation of dietary flavan-3-ols and the bioactivity of their metabolites," Food \& Function, vol. 1, no. 3, pp. 233-253, 2010.

[126] C. D. Kay, G. Pereira-Caro, I. A. Ludwig, M. N. Clifford, and A. Crozier, "Anthocyanins and flavanones are more bioavailable than previously perceived: a review of recent evidence," Annual Review of Food Science and Technology, vol. 8, no. 1, pp. 155-180, 2010.

[127] P. Posadzki, L. Watson, and E. Ernst, "Herb-drug interactions: an overview of systematic reviews," British Journal of Clinical Pharmacology, vol. 75, no. 3, pp. 603-618, 2013. 
[128] A. Sood, R. Sood, F. J. Brinker, R. Mann, L. L. Loehrer, and D. L. Wahner-Roedler, "Potential for interactions between dietary supplements and prescription medications," American Journal of Medicine, vol. 121, no. 3, pp. 207-211, 2008.

[129] B. Caballero, Guide to Nutritional Supplements, Academic Press, Amsterdam, Netherlands, 2009.

[130] B. Ge, Z. Zhang, and Z. Zuo, "Updates on the clinical evidenced herb-warfarin interactions," Evidence-Based Complementary and Alternative Medicine, vol. 2014, Article ID 957362, 18 pages, 2014.

[131] C. Ulbricht, W. Chao, D. Costa, E. Rusie-Seamon, W. Weissner, and J. Woods, "Clinical evidence of herb-drug interactions: a systematic review by the natural standard research collaboration," Current Drug Metabolism, vol. 9, no. 10, pp. 1063-1120, 2008.

[132] J. I. Boullata and A. M. Nace, "Safety issues with herbal medicine," Pharmacotherapy, vol. 20, no. 3, pp. 257-269, 2000.

[133] A. A. Izzo and E. Ernst, "Interactions between herbal medicines and prescribed drugs: a systematic review," Drugs, vol. 78, no. 1, pp. 184-191, 2000.

[134] T. H. Wideman, G. G. Asmundson, R. J. Smeets et al., "Rethinking the fear avoidance model: toward a multidimensional framework of pain-related disability," Pain, vol. 154, no. 11, pp. 2262-2265, 2013.

[135] M. B. Stargrove, J. Treasure, and L. D. McKee, "Herb, Nutrient, and Drug Interactions," in Clinical Implications and Therapeutic Strategies, Humana Press, Totowa, NJ, USA, 2013.

[136] M. T. Holmberg, A. Tornio, M. Neuvonen, P. J. Neuvonen, J. T. Backman, and M. Niemi, "Grapefruit juice inhibits the metabolic activation of clopidogrel," Clinical Pharmacology and Therapeutics, vol. 95, no. 3, pp. 307-313, 2014.

[137] M. T. Holmberg, A. Tornio, L. Joutsi-Korhonen et al., "Grapefruit juice markedly increases the plasma concentrations and antiplatelet effects of ticagrelor in healthy subjects," British Journal of Clinical Pharmacology, vol. 75, no. 6, pp. 1488-1496, 2014.

[138] Y. Sawada, S. Hori, H. Ohtani, T. Ikemoto, A. Miki, and K. Taniguchi, "Possible case of potentiation of the antiplatelet effect of cilostazol by grapefruit juice," Journal of Clinical Pharmacy and Therapeutics, vol. 32, no. 5, pp. 457-459, 2014.

[139] Z. Kyselova, "Toxicological aspects of the use of phenolic compounds in disease prevention," Interdisciplinary Toxicology, vol. 4, no. 4, pp. 173-183, 2011.

[140] H. S. Lee, "Antiplatelet property of Curcuma longa L. rhizome-derived ar -turmerone," Bioresource Technology, vol. 97, no. 12, pp. 1372-1376, 2006.

[141] WebMD, "Drug interaction checker," https://wwwwebmdcom/ interaction-checker.

[142] M. Ekor, "The growing use of herbal medicines: Issues relating to adverse reactions and challenges in monitoring safety," Frontiers in Neurology, vol. 4, pp. 1-10, 2006.

[143] M. Ebadi, Pharmacodynamic Basis of Herbal Medicine, CRC Press, Boca Raton, FL, USA, 2006.

[144] E. Mendes, M. T. Herdeiro, and F. Pimentel, "The use of herbal medicine therapies by cancer patients," Acta Medica Portuguesa, vol. 23, no. 5, pp. 901-908, 2010. 